Relative Burnup Values and Cooling Times of Irradiated MTR Fuel Elements

응

to

$\frac{2}{\omega}$

를 


\title{
Nondestructive Verification of \\ Relative Burnup Values and Cooling Times of Irradiated MTR Fuel Elements
}

\author{
J. R. Phillips \\ T. R. Bement \\ K. Kaieds" \\ E. G. Modina
}

"Visiting Scientist. Japan Atomic Energy Research Institute, Tokai-Mura, JAPAN.
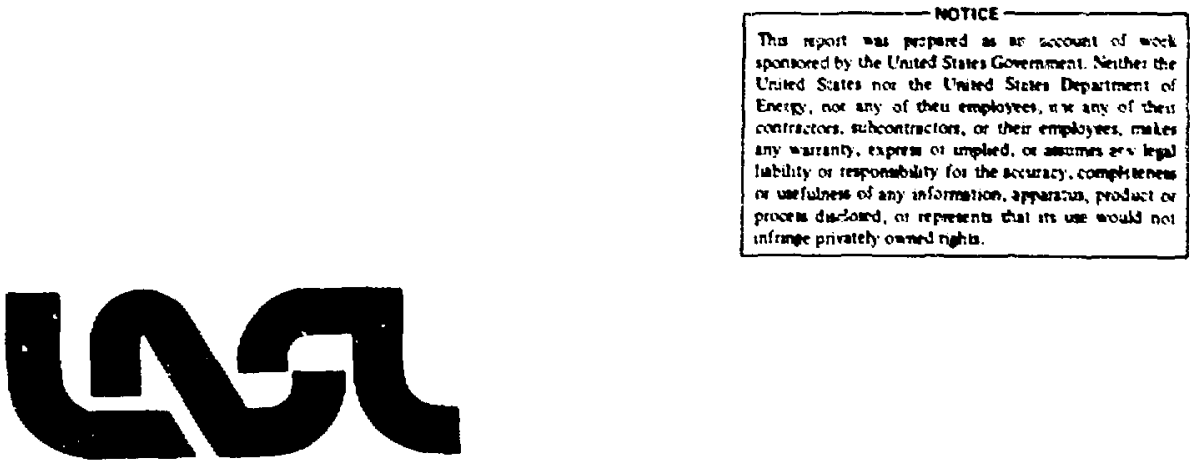


\title{
NONDESTRUCTIVE VERIFICATION OF REATIVE BURUUP VLUES AND

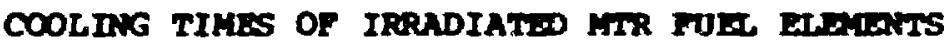

\author{
by
}

J. R. Phillips, T. R. Bement, K. Kaieda, and E. G. Medina

\begin{abstract}
Sixteen irradiated MrR fuel elements have been examined using nondestructive gawa-ray and neutron techniques. The consistency of declared burnup values and cooling times has been measured. Measured parameters have been identified that best predict the burnup and cooling time values of individual elements and their relative importances have been quantified using established statistical methods of analysis, Various detector systens, including germanium, cadmiun telluride, and $B e(Y, n)$ detector, and fission chamber have been used to measure the axial activity profiles.
\end{abstract}

\section{INTRODUCTION}

Nuclear pawer has been projected to supply a significant fraction of the total electricity output of the world by the year 2000.1 Light-water reactors using low-enriched uranium ( $\left.03.52^{235} \mathrm{U}\right)$ have generated more than 260 million megawatt days (MWD) of electrical energy over the past three decades. $^{2}$ A significant by-product of the fissioning process is the production of plutonium which can be used as fuel material for a nuclear explosives program. The accurate measurement and accountancy of the plutonium inventory of discharged light-water reactor fuels is an integral part of the total systear of safeguards for the nuclear fuel cycle.

The Safeguards Technology Groups of the Los Alamos Scientific Laborztory have been actively investigating the problens associated with safeguarding irradiated fuels for the past two years. Many of the available nondestructive techniques and applications were reviewed as the background for an experimental 
progran. 3 Nondestructive gama-ray and passive neutron techniques were selected as being the most applicable to the characterization of irradiated fuels. The plutonium inventory of an irradiated assembly cannot be measured directly using these techniques, therefore an indirect signature, that can be analytically related to the plutonium content, must be measured. Burnup is a measurable paraneter that satisfies this condition. Burnup, defined as the integrated energy released from the fission of heavy nuclides initially present in the fuel, or as the percent of initial ${ }^{235} \mathrm{U}$ consumed, can be related directly to the remaining ${ }^{235} \mathrm{O}$ inventory as well as the plutonium produced. To determine the absolute burnup value of an individual fuel assembly independently of reactor history, the cooling time must be verified because the paraneters measured are all time-dependent. The examination of an irradiated fuel assembly will usually occur after a significant time ( $\mathrm{k}-5 \mathrm{yr}$ ) following discharge. Many of the gamma-ray and neutron signatures have half-lives off the same order as the cooling times, therefore the results must be corrected to obtain a consistent set of data.

Initially our investigations are primarily concerned with the development of gamma-ray and neutron techniques for burnup determination which involve also the determination of the cooling time. The original work was performed on highly-enriched Materials Test Reactor (MTR) fuel from the Omega West Reactor located at Ios Alamos. The ease of access to the reactor as well as the ability to control the environment in which the examinations were performed provided a unique opportunity to test and evaluate techniques which could be applied to the characterization of Light Water Reactor (LWR) fuels at various reactor sites.

\section{A. Previous Investigations}

Several other gamma-ray examinations of irradiated MTR fuel assemblies have been performed. Dragnev et al concluded that the ${ }^{144} \mathrm{Pr} /{ }^{137} \mathrm{Cs}$ activity ratio was a suitable cooling time monitor fior cooling times ranging from 0.5 to 5 years. 4 They obtained an average error of 4.68 for the measured cooling times when compared with the operator's declared values. The ${ }^{134} \mathrm{Cs}(796 \mathrm{keV}) /{ }^{137} \mathrm{Cs}(662 \mathrm{keV})$ ratio with the correction for cooling times represented the burnup values with an average precision of 4.98 . Beets reported the use of the ${ }^{95} \mathrm{zr} / \mathrm{Nb}$ artivity ratio as a convenient cooling time monitor for periods from several days up to one year, but better accuracy can be achieved from calibrated ${ }^{95} \mathrm{zr} /{ }^{137} \mathrm{Cs}$ measurements. 5 The applications 
of ${ }^{137} \mathrm{Cs}$ activity and ${ }^{134} \mathrm{Cs} /{ }^{137} \mathrm{Cs}$ activity ratio as burnup monitors were discussed with a relative precision of 98 for the ${ }^{134} \mathrm{cs} /{ }^{137} \mathrm{Cs}$ results. These two investigations were based upon irradiated MTR fuel elements. Hanno recentiy published a rather complete evaluation of the experinental measurement of highly-enriched fuel elements for determination of cooling times and burnup values. ${ }^{6,7}$ This work was compared with similar examinations performed by Dragnev. The importance of neutron flux density during the irradiation of the assemblies was identified as one of the more critical parameters.

Other investigators have examined the application of nondestructive gamaray techniques for verification of burnup and cooling times in natural uranium fuels. ${ }^{8,9}$ valovic reported measuring burnup with a precision of 68 by comparing ${ }^{137} \mathrm{Cs}$ activities of the assemblies to a known reference assembly. Measurement of cooling times exhibited a 7-158 precision between declared and measured values. ${ }^{9}$ An average difference of 2.28 between the ${ }^{134} \mathrm{Cs} /{ }^{137} \mathrm{Cs}$ analysis and the mass spectrometric results for 20 fuel elements was reported by Chen in the examination of CaNDU fuels. ${ }^{8}$ This report explored the possibility of calculating the integrated flux by relating calculated and measured ${ }^{134} \mathrm{Cs} /{ }^{137} \mathrm{Cs}$ ratios.

\section{B. LASL Investigation}

Sjxteen irradiated MIR fuel elements with similar irradiation histories were measured nondestructively to evaluate which isotopic activities and/or isotopic ratios best explained the variation in cooling times and burnup. The declared cooling times ranged from 438 to 1456 days and the declared burnup vaiues ranged from 27.44 to 33,48 atom percent. Axial scans were performed on four elements to investigate the correlation between the results obtained using rapid profile detectors and the results from the more detailed germanium data. These results have been applied to defining the critical parameters in the subsequent examinations of BWR and PWR fuels.

\section{EXPERIMENTAL}

The Omega West Reactor (OWR) is a B-MW thermal, heterogeneous, tank-type research reactor which utilizes aluminum-clad fuel elements of the Materials Testing Reactor (MTR) type. The reactor core consists of a $4 \times 9$ array of fuel elements with each containing approximately $220 \mathrm{~g}$ of ${ }^{235} \mathrm{U}$ (938 enrichment). Each fuel element is constructed of 18 curved fuel plates, $1.52 \mathrm{~mm}$ $(0.060$ in.) thick mounted $2.97 \mathrm{~mm}(0.117 \mathrm{in.})$ apart in heavy aluminum side 
plates. Each fuel plate contains a $61-\mathrm{cm}$ (24 in.) long sheet of uraniumaluminum alloy that is sandwiched and hot rolled between two $0.51 \mathrm{~mm}$ (11).020 in.) thick sheets of pure aluminum. 10

The sixteen irradiated elements examined during the two exercises are listed in Table I. Operator-declared burnup values range from 27.44 to 33.48 at. (61.36 to $73.87 \mathrm{~g})$, with cooling times ranging firom 438 to 1456 days. The specific burnup values were calculated from the irradiation history of the reactor and may have a significant error of approximately 58. The reactor is operated as a research facility and has a very irregular operation history. A typical two-week reactor history is schematically presented in Fig. 1. During this period the reactor was only operated eight hours/day and at various power levels ranging from a relative minimum of 0.44 to a maximum of 1.0 . This irregular operation introduced additional complications in the calculaticns of the theoretical activity levels of isotopes and isotopic ratios.

Four nondestructive techniques were investigated for the characterization of irradiated MTR fuels: gamma-ray techniques included the use of germanium detectors, cadmium telluride detectors and beryllium $(\gamma, n)$ detectors; the neutron technique was based on the use of fission chambers.

There are two basic objectives in the examination of irradiated fuels for safeguards. The first is to determine the consistency of the relative burnup of individual fuel elements independently of any operator-supplied information and to determire if there are any values which lie outside specified limits (958 confidence bounds). Fhis may be possible to accomplish by measuring the entire fuel element by gamma-ray and/or neutron methods which provide data that is correlated to the operatcs-declared burnup values. The second objective is the rapid measurement of the axial activity profile of the fuel elements. The axial protile measurement is essential to ensure that a segment of the fuel element has not been removed, thereby establishing the physical

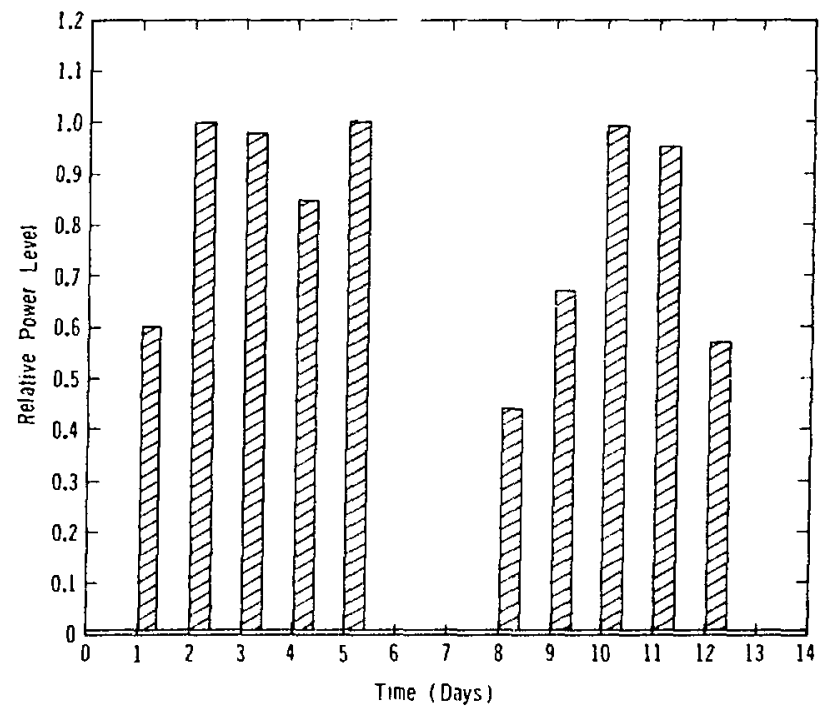

Fig. 1. Two-week irradiation history of a fuel element in the Omega West Reactor. 
TABLE I

MTR FUEL ELEMENTS NONDESTRUCTIVELY MEASURED

Fue 1

\begin{tabular}{|c|c|c|c|c|c|}
\hline $\begin{array}{c}\text { Element } \\
\text { No. }\end{array}$ & $\begin{array}{l}\text { Atom } 8 \\
\text { Burnup }\end{array}$ & $\begin{array}{l}\text { Grams } \\
\text { Burnup }\end{array}$ & $\begin{array}{c}\text { Discharge } \\
\text { Date } \\
\end{array}$ & $\begin{array}{c}\text { Bxamination } \\
\text { Dates }\end{array}$ & \\
\hline E356 & 33.48 & 73.87 & $1 / 17 / 74$ & $9 / 29 / 77$ & \\
\hline $\begin{array}{l}\text { E357 } \\
\text { E359 } \\
\text { E361 }\end{array}$ & $\begin{array}{l}32.84 \\
31.62 \\
30.11\end{array}$ & $\begin{array}{l}71.64 \\
69.46 \\
67.12\end{array}$ & $\begin{array}{l}1 / 17 / 74 \\
4 / 8 / 74 \\
6 / 13 / 74\end{array}$ & $\begin{array}{l}9 / 28 / 77 \\
9 / 28 / 77\end{array}$ & $\begin{array}{l}1 / 12 / 78 \\
1 / 11 / 78\end{array}$ \\
\hline $\begin{array}{l}\text { E363 } \\
\text { E364 }\end{array}$ & $\begin{array}{l}30.99 \\
28.89\end{array}$ & $\begin{array}{l}69.27 \\
63.40\end{array}$ & $\begin{array}{l}6 / 13 / 74 \\
10 / 3 / 74\end{array}$ & $\begin{array}{l}9 / 30 / 77 \\
9 / 29 / 77\end{array}$ & \\
\hline E368 & 29.15 & 65.15 & $2 / 24 / 75$ & $9 / 29 / 77$ & $1 / 12 / 78$ \\
\hline E370 & 27.74 & 61.36 & $4 / 21 / 75$ & $9 / 29 / 77$ & $1 / 13 / 78$ \\
\hline E37 1 & 27.44 & 61.36 & $4 / 2 ! / 75$ & $9 / 28 / 77$ & \\
\hline E37\% & 31.52 & 70.28 & $9 / 8 / 75$ & $9 / 28 / 77$ & \\
\hline $\begin{array}{l}E 373 \\
E 374\end{array}$ & $\begin{array}{l}32.17 \\
29.47\end{array}$ & $\begin{array}{l}70.54 \\
65.65\end{array}$ & $\begin{array}{l}9 / 8 / 75 \\
11 / 1 / 77\end{array}$ & & $\begin{array}{l}1 / 13 / 78 \\
1 / 13 / 78\end{array}$ \\
\hline $\begin{array}{l}\text { P375 } \\
\text { E373 }\end{array}$ & $\begin{array}{l}30.73 \\
29.29\end{array}$ & $\begin{array}{l}68.38 \\
65.37\end{array}$ & $\begin{array}{l}3 / 1 / 76 \\
3 / 22 / 76\end{array}$ & $9 / 28 / 77$ & $1 / 13 / 78$ \\
\hline $\begin{array}{l}\text { E379 } \\
\text { E383 }\end{array}$ & $\begin{array}{l}29.78 \\
28.95\end{array}$ & $\begin{array}{l}66.22 \\
63.37\end{array}$ & $\begin{array}{l}3 / 22 / 76 \\
8 / 16 / 76\end{array}$ & & $\begin{array}{l}1 / 13 / 78 \\
1 / 11 / 78\end{array}$ \\
\hline
\end{tabular}

oimensions of the element. Also, if the relative burnup has been established at only one or a few points by more detailed analysis, the profile can be used as an integrating function to establish the integral burnup cf the element.

The experimental apparatus is schematically represented in Fig. 2 . The germanium detector was mounted on a moveable platform with a fan-shaped collinator attached. To obtain an axial scan of an irradiated fuel element, the detector-collimator assembly was translated along the principal axis. Complete gamma-ray spectra were recorded at specified axial positions and stored on magnetic media for future reference. A typical gama-ray spectra with the major full-energy peaks identified is shown in Fig. 3. The extremely high gamma activity required the insertion of lead as an attenuator which explains the relatively flat energy spectra. Because only relative activities were being determined, the gamma-ray spectra were not corrected for differences in relative efficiencies as a function of gamma-ray energy.

The collimator was rotated 90 degrees permitting the entire fuel element to be examined for the measurements. This reduced the position sampling problem to a second order effect of geometry $\left(1 / R^{2}\right)$. That is, the effects of any anomalies in the axial profiles were reduced by examining the entire fuel element. 


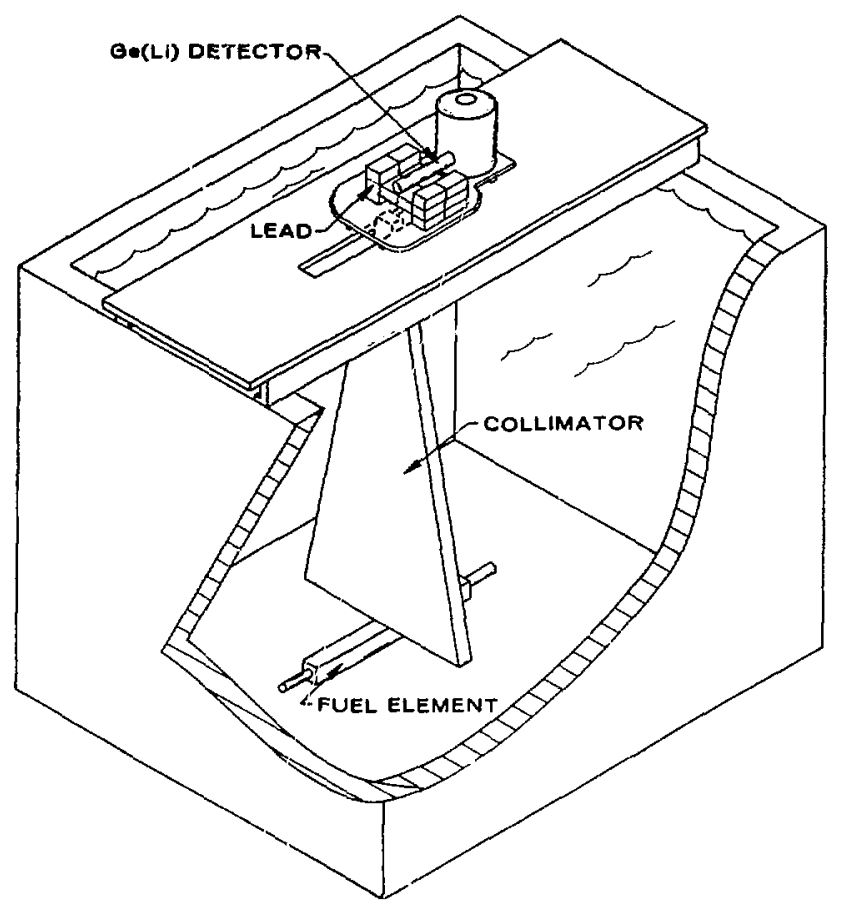

Fig. 2 .

Germanium detector and collimator assembly for collection of integral gamma-ray spectra and isotopic axial profiles.

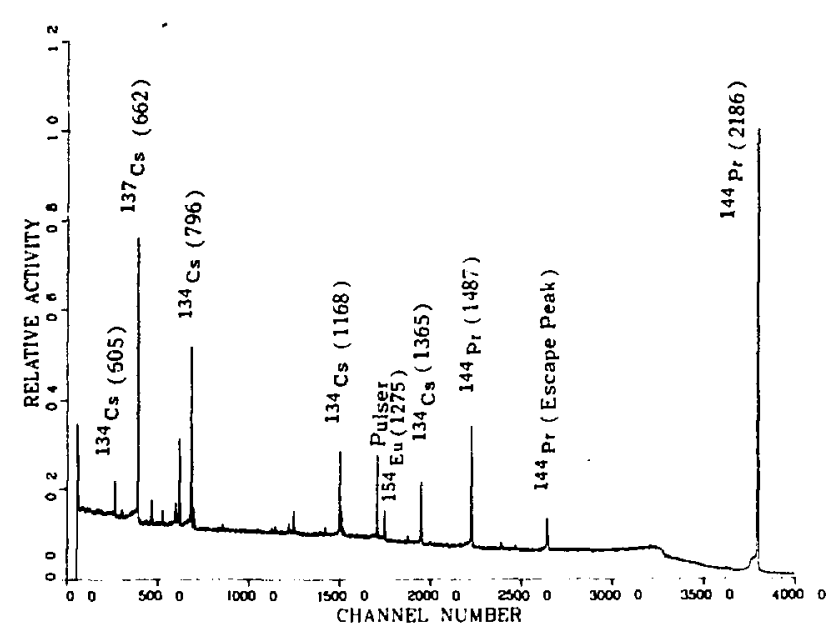

Fig. 3.

Typical gamma-ray spectra showing the principal full-energy peaks.

The procedure for the examination of an individual fuel element involved the transfer of the element from the reactor storage rack to an isolated examination pond 2.4 meters deep. Only one fuel element was in the pond at a time. All of the examinations were performed during a scheduled reactor maintenance period.

The axial profiles of four fuel elements were measured using the germanium detector system. Cadmium telluride detection of the gross gamma activities were recorded on two fuel elements. The higher-energy gross gamma activity profile was obtained using the beryllium $(\gamma, n)$ detector. A high-energy gamma ray (2.186 MeV) can undergo an interaction with Be producing a neutron with an average energy of $510 \mathrm{keV}^{11}$ which after being mode-ated is detected using a ${ }^{235} \mathrm{U}$ fission chamber. A drawing of the $\mathrm{Be}(r, n)$ detector in Fig. 4 shows the relative location of the principal components. The fission chamber was surrounded by a $4-\mathrm{cm}$ thick polyethylene annulus to moderate the neutrons emitted 
from the beryllium (Be) converter. Referring to the typical gamma-ray spectra (Fig. 3), the principal gammaray interacting with the $\mathrm{Be}$ and producing neutrons is the $2186-\mathrm{keV}$ gamma ray of the fission product ${ }^{144} \mathrm{Pr}$. The ${ }^{144} \mathrm{Pr}\left(t_{1 / 2}=17.28 \mathrm{~m}\right)$ is in secular equilibrium with its parent ${ }^{144} \mathrm{Ce}\left(t_{1 / 2}=284.4\right.$ d) ${ }^{12}$, therefore, the axial profile obtained from this detector will represent the more recent irradiation exposure of the

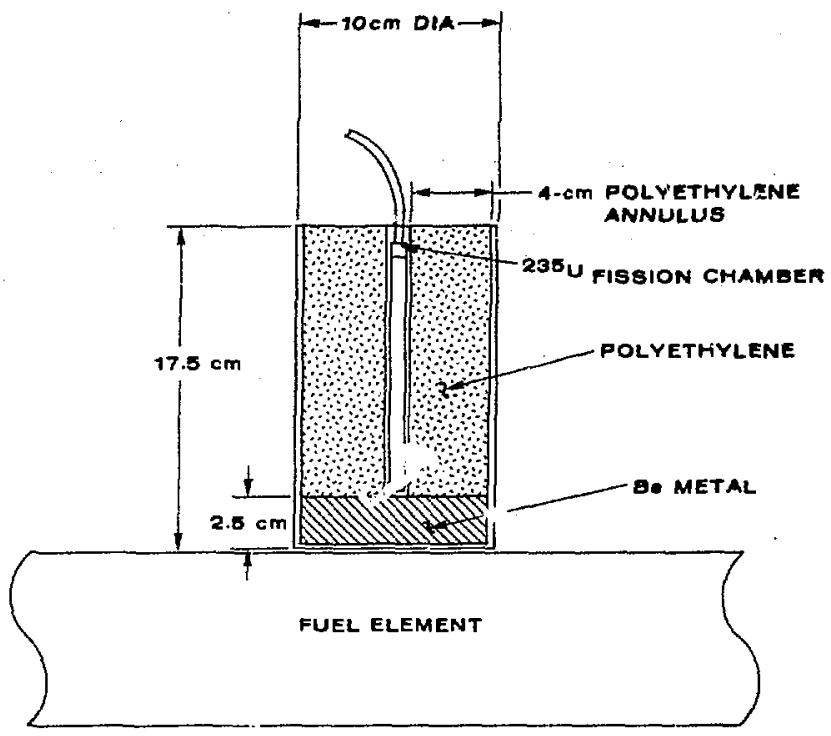
fuel element. The possible interference of spontaneous fission neutrons emitted from the fuel element was determined to be insignificant by Fig. 4. Beryllium $(\gamma, n)$ detector for measuring the high-energy gamma-ray profile. removing the Be converter and measur-

ing the fission chamber response. Spontaneous fission neutrons are primarily produced by the spontaneous fissioning of ${ }^{242} \mathrm{Cm},{ }^{244} \mathrm{Cm}$ and the evennumbered $\mathrm{Pu}$ isotopes. Since this fuel contained only $78238 \mathrm{U}$, the production of these transuranic isotopes should have been minimal.

Various thicknesses $(0.5,1.0,2.0,3.0$, and $4.0 \mathrm{~cm})$ of the polyethylene annulus were evaluated prior to the selection of the 4-cm thick annulus for moderating the neutrons. Thicker discs of Be did not improve the efficiency of the detector assembly. The design of a $B e(\gamma, n)$ detector was dependent upon the physical constraints and the specific fission chamber used to detect the neutrons.

A small cadmium telluride gamma detector was also used to monitor the axial gross gamma profiles of the irradiated fuel elemerts. The detector was placed in a small tube with a lead shield (first exercise) and a tungsten alloy shield (second exercise) to reduce the intense clamma field. In both cases, the shielding was insufficient to operate the caTe in the pulse counting mode. The detector became saturated at any position closer than 80-cm to the fuel elements.

The relative neutron profile was measured with a large fission chamber with a $1.6 \mathrm{~g}$ Joading of ${ }^{235} \mathrm{U}$. This loading was forty times larger than the loading of the small fission chamber $\left(38.6 \mathrm{mg}{ }^{235} \mathrm{U}\right.$ ) in the $\mathrm{Be}(\gamma, \mathrm{n})$ detector. 


\section{RESULTS}

\section{A. Statistical analyses for cooling time ard burnup measurements}

The objective of the analyses was to determine what variable or group of variables provided the best prediction of cooling time and burnup. The variables included specific activities of fission products, and ratios of activities. The criterion used to pick a predictor (or set of predictors) was the squared simple (or multiple) correlation coerficient $\left(R^{2}\right)$. The quantity $R^{2}$ is expressed as

$$
R^{2}=\frac{\left(\hat{Y}_{i}-\bar{Y}\right)^{2}}{\left(Y_{i}-\bar{Y}\right)^{2}}
$$

where $\hat{Y}_{i}$ is the $i$ th observation, $\bar{Y}$ is the mean of the $Y_{i}$ 's and $\hat{Y}_{i}$ is the estimated value obtained from the regression equation. $R^{2}$ is the proportion of the total variation about che mean $\bar{Y}$ explained by the regression: ${ }^{13}$ It is often expressed as a percentage by multiplying by 100 . The $R^{2}$ value will be used throughout the renainder of the paper as a measure to quantify the degree of relationship between burnup or cooling time and measured variables.

A total of 33 gamma-ray peaks and isotopic ratios were considered as possible candidates for predictions. Consideration of all possible sets of predictions was impossible for two reasons. First, if all possible sets were considered, this would involve $2^{33}-1$ (or more than $8 \times 10^{9}$ ) separate linear regressions. Second, it was impossible or impractical to consider predictor sets containing large numbers of variables because of the limited amount of data available and because of the desire to keep the equations as simple as possible.

Several techniques were used to find predictor sets as nearly optimal as possible. Stepwise multiple regression ${ }^{13}$ was used but a straightforward application of this procedure proved inadequate. Stepwise regression does not necessarily lead to maximum $R^{2}$ for a set of data. A greater problem was the fact that stepwise regression analysis resulted in the selection of different sets of predictors for the two exercises. Other multivariate data alalysis procedures were used to recoucile these differences and to arrive at a set of predictors that did a good job in each exercise. 
The motivation for using the multivariate tect.niques was to determine if the 33 predictor candidates could be divided into smaller groups on the basis of their information content. Such groupings could be useful for two reasons. One is to assure that variables containing information not present in any other variables are not arbitrarily excluded from consideration in the prediction equation. Secondly, if such groupings could be achieved, then it might not be necessary to uso more than one variable from a group in a prediction equation. On the other hand, variables that do not fall in a well-defined group might have unique information to offer concerning the depuddent variables. It is also possible that such predictor variables simp.' $Y$ contain information which is ccntained in two or more of the other groups of iariables.

The procedures used tc examine the multivariate structure of the peaks and ratios were principal component analysis ${ }^{14}$ and cluster analysis.15,16 Principal component analysis was used to determine the number of dimensions required to contain most of the variation in the independent variables. Each dimension is a linear combination of the variables and is not necessarily a specific variable. If it is determined that most of the variation in the predictor variables is confined to a small number of dimensions, possibly two or three, it may be possible to separate these variables into groups with different information content. Ideally, one would like the information content of all groups to be mutuálly exclusive and exhaustive. This, however, can seldom, if ever, be achieved in practice.

Cluster analysis was used as an exploratory technique to search for groupings of the 33 preãictor variables. From the principal component analysis we determined that most of the variation in the predictor variables was confined to a small number of dimensions, cluster analysis provided a qualitative method of grouping variables that would provide similar information. The selection of one variable fror. ach grouping could provide sufficient information, whereby if we had select \& two variables from a single grouping it is likely that we would not have significantly increased our total inflormation about the set of data. Functionally we were attempting to obtain a relationship between a minimal number of measured variables and relative cooling times or burnups of individual assemblies. This can be illustrated by the following equation

Cooling Time or Burnup $\alpha f\left(c_{1}, c_{2}, c_{3}, \ldots\right)$, 
where $c_{i}$ is a varlable from the ith cluster. A cluster can consist of a aingle variable and that would imply the variable could provide unique inforation with respect to the dependent variable (cooling time or burnup).

Several hierarchical clustering algorithas were applied to the 33 variables using the complement of the correiation coefficient $(1-r)$ as $a$ measure of the distance between variables. The furtherest neighbor (or complete linkage) algorithm was used as the primary means of separating the variables into groups. This algorithm has the property of exaggerating dista be ween variables. Sone groupings were found which appeared in both extrstses and these helped to resolve inconsistencies in stepwise regression results.

The statistical procedures described here were used to provide supplementary information for variable selection. They were not used with the intention of providing conclusive results and in fact, could not have done so with the relative small sample sizes available. They did, however, make it possible to look for patterns of relationship among a large number of variables which might otherwise escape one's attention.

B. Consistency of Relative Cooling Times

All of the gamma-ray and neutron signatures of irradiated fuel assemblies aie functiors of time-dependent variables. Therefore the measurements must be corrected for cooling times to permit the meaningful correlation between the declared and measured burnup values. Statistical analysis techniques were applied to the gamma-ray data to assist in the selection of specific variables for predicting the cooling times of individual fuel assemblies. In this investigation we assumed that the irradiation histories were similar for the set of fuel elements.

Cooling time can be expressed as the following:

$$
t_{c}=-\frac{1}{\lambda_{i}} \ln \frac{A_{i}}{A_{o i}} \quad \text { for a single isotope }
$$

and

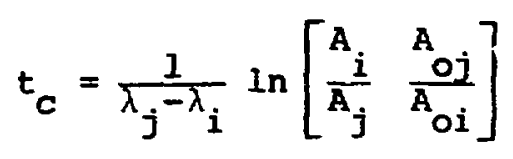


for the ratio of two isotopes with $\lambda_{i}$ the decay constant, $A_{i}$ " the measured isotopic activity at time $t_{c}$, and $A_{\text {oi }}$ the activity of the ith isotope at $t_{c}=0$ for end of irradiation). $A_{0}$ will be a function of the reactor history wich is in reality a tine-dependent function. Both of the above functions for $t_{c}$ can be approximated by a linear function when $t_{c}$ and $\left(\lambda_{j}-\lambda_{i}\right) t_{c}$ are small values.

For the relationship of two activities, there are two genera? classifications of isotopes. The first group consists of ratios with both isotopes being a direct fission product and therefore directly proportional to the integrated flux (assuring the absorption cross-section is small). The isotopes in this group consist of ${ }^{137} \mathrm{Cs}\left(t_{\frac{1}{2}}=30.12 \mathrm{yr}\right) \cdot{ }^{144} \mathrm{Ce}-{ }^{144} \operatorname{Pr}\left(t_{\frac{1}{2}}=284.4\right.$ days), and ${ }^{106} \mathrm{Ru}-{ }^{106} \mathrm{Rh}\left(t_{\frac{1}{2}}=369\right.$ days) which were measureable in the spectra we obtained from this set of assemblies. The second group consists of ${ }^{134} \mathrm{Cs}\left(t_{\frac{1}{2}}=2.06 \mathrm{yr}\right)$ and ${ }^{154} \mathrm{Eu}\left(t_{1}=8.6 \mathrm{yr}\right.$ ) which results fron the $(n, y)$ reaction on the fission products ${ }^{133} \mathrm{Cs}$ and ${ }^{153} \mathrm{Eu}$, respectively. In these cases

$$
t_{c}=\frac{1}{\lambda_{2}-\lambda_{1}} \ln \frac{A_{1}}{A_{2}}+f(\phi, \beta) .
$$

where $A_{1}$ is proportional to $\phi^{B}$ with $1<B \leqslant 2$ and $A_{2}$ is proportional to $\phi$. The $f(\phi, \beta)$ is a function of the integrated flux and the exponent $B$. The functional reiatiorsib of $B$ with respect to the integrated flux (or burnup) of various elements will be discussed in the section on the axial measurements.

Two basic approaches to the solution of the relationship of measured gammaray activities with declared cooling times were investigated. (1) The irst model used known coefficients for $1 / \lambda$ and $1 /\left(\lambda_{2}-\lambda_{1}\right)$ and solved for the average In $A_{0}$ and $\ln \left(A_{02} / A_{01}\right.$ ' values. These averages were then used in place of the individual values in expressing the relationship between activity and cooling time. (2) The second model was a simple linear relationship between cooling time and activity at time, $t_{c}$. Each technique requires assumptions that can limit its applicability under certain circumstances. Each approach will be discussed in detail in the following subsections. 
1. Model Using Known Decay Constants. In this section we assume that the following relationship is true for individual isotopes

$$
A_{i}=A_{o i} e^{-\lambda_{i} t} c
$$

or

$$
t_{c}=\frac{1}{\lambda_{i}} \ln A_{O i}-\frac{1}{\lambda_{1}} \ln A_{i}
$$

where $A_{i}=$ measured activity of the ith isotope after cooling time, $t_{c}$

$A_{O i}=$ actual activity of the ith isotope at the end of irradiation

$\lambda_{i}=$ decay constant of ith isotope

$t_{c}=$ cooling time.

For isotopic ratjos where each isotope is proportional to the integrated flux, $\phi$, or each isotope is proportional to $\phi^{\beta i}$ where $1<\beta_{i}<2$ and $\beta_{i}$ is not significantly different from $\beta_{j}$ the following is true

$$
t_{c}=\frac{1}{\lambda_{2}-\lambda_{1}} \ln \left(\frac{A_{1}}{A_{2}}\right)+\frac{1}{\lambda_{2}^{-\lambda} 1} \ln \left(\frac{A_{o 2}}{A_{o 1}}\right) .
$$

Note that neither equation includes any error term. Therefore all the variability must be attributed to $\left(A_{O i}\right)$ and $\left(A_{02} / A_{O 1}\right)$ for the single isotope and the ratio variables. Since $A_{0 i}$ and $\left(A_{02} / A_{01}\right)$ are unknown and cannot be determined without knowledge of $t_{c}$ the values $\left(\ln A_{O 2}\right)$ and $\ln \left(A_{O 1} / A_{O 2}\right)$ have to be estimated based upon the data that is available. Therefore the estimate of $t_{c}$ based upon a single isotope is

$$
\hat{t}_{c}=\frac{1}{\lambda}\left[\overline{\ln A_{0}}-\ln A_{i} \mid\right.
$$

where $\overline{\operatorname{In} A_{0}}$ is the average in $A_{0}$ value determined from the set of assemblies examined. Similarly, for the ratio data, the following relationship is true

$$
\hat{t}_{c}=\frac{1}{\lambda_{2}-\lambda_{1}}\left[\overline{\ln \left(\frac{A_{02}}{A_{01}}\right)}+\ln \left(\frac{A_{1}}{A_{2}}\right)\right] \text {. }
$$


For the single isotopes the $\left.{ }^{134} \mathrm{Cs} / 605 \mathrm{keV}\right),{ }^{106} \mathrm{Rh}(1050 \mathrm{keV})$ and ${ }^{144} \operatorname{Pr}(1487 \mathrm{keV})$ activities provided the most consistent data related to cooling times as shown in Table II. The average differences for ther ingle isotopes ranged from 5.17 to 10.7t. The results for the best four 1sotopic ratios are given in Table III with the average scatter in the values rangling from 2.78 to 7.88 . These differences corresponded to errors as large as one hundred days which can result in over a 30 error in correcting the neasured activity to the activity at discharge for isotopes with half-lives of 300 days ( ${ }^{144} \mathrm{Ce}-{ }^{144} \mathrm{Pr} ; t_{z_{2}}=284.4$ days) and ( ${ }^{106} \mathrm{Ru}-{ }^{106} \mathrm{Rh} ; t_{l_{2}}=369$ days).

To obtain an estimate of the variance of the differsnce between $\hat{t}_{c}$ and the true $t_{c}$ for a particular element we can calculate the following if we assume $\overline{\ln A_{0}}$ and $\ln A_{i}$ are independent for the single isotope.

$$
\operatorname{Var}\left(\hat{t}_{c}-t_{c}\right)=\frac{1}{\lambda}\left[\operatorname{Var}\left(\ln A_{0}\right)(1+1 / N)+\operatorname{Var}(\ln A)\right] .
$$

Making similar assumptions for the ratio of two isotopes

$$
\operatorname{var}\left(\hat{t}_{c}-t_{c}\right)=\left(\frac{1}{\lambda_{2}-\lambda_{1}}\right)^{2}\left[\operatorname{var}\left(\ln \frac{A_{O 2}}{A_{o 1}}\right)(1+1 / N)+\operatorname{var}\left(\ln \frac{A_{1}}{A_{2}}\right)\right]
$$

The assumptions of independence are reasonable if the element in question were not used to compute $\overline{\ln A_{0}}$.

In each of the above cases it can be seen that the variance of $\left(\hat{t}_{c}-t_{c}\right)$ is composed of two farts; the first due to using the average log discharge activity to estimate the actual discharge activity and the second due to variation in activities at time $t_{c}$. It can be shown that for data similar to that reported here, the first source of variation is the major contributor to $\operatorname{Var}\left(\hat{t}_{c}-t_{c}\right)$. In Table IV the standard deviation of $\left(\hat{t}_{c}-t_{c}\right)$ (the square rot of the variance) is listed for the best single isotopes and for the best ratios. Values of $\operatorname{var}\left(\overline{\ln A_{0}}\right), \operatorname{Var}(\ln A), \operatorname{var}\left[\ln \left(A_{02} / A_{01}\right]\right.$, and $\operatorname{var}\left[\ln \left(A_{01} / A_{02}\right)\right]$ typical of those found in this exercise were used to generate the table. 
were 17

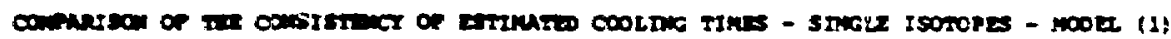

Desente

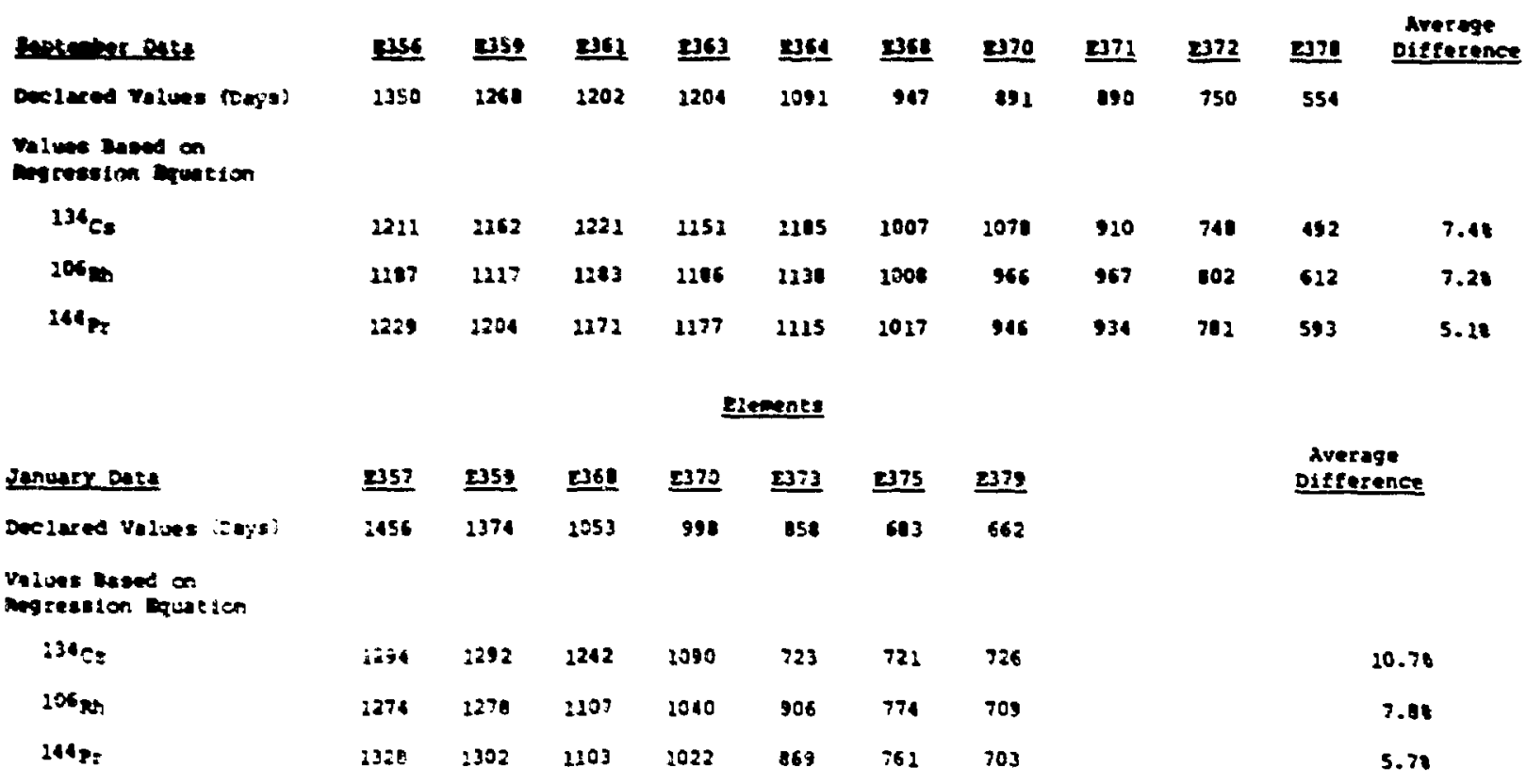

TALE III

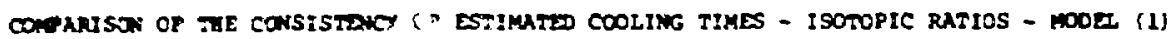

Elements

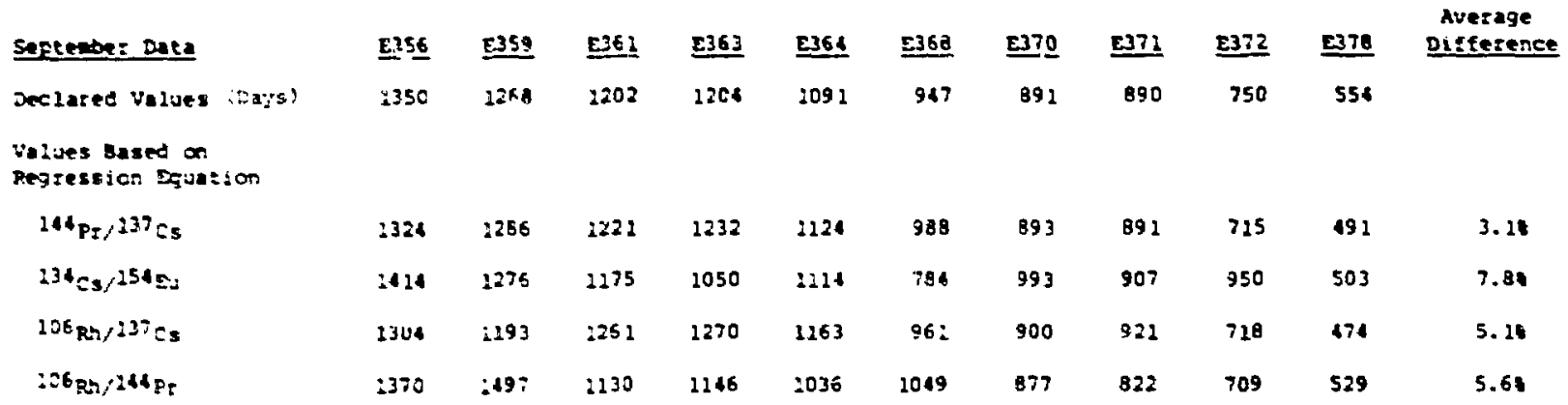

\section{Elements}

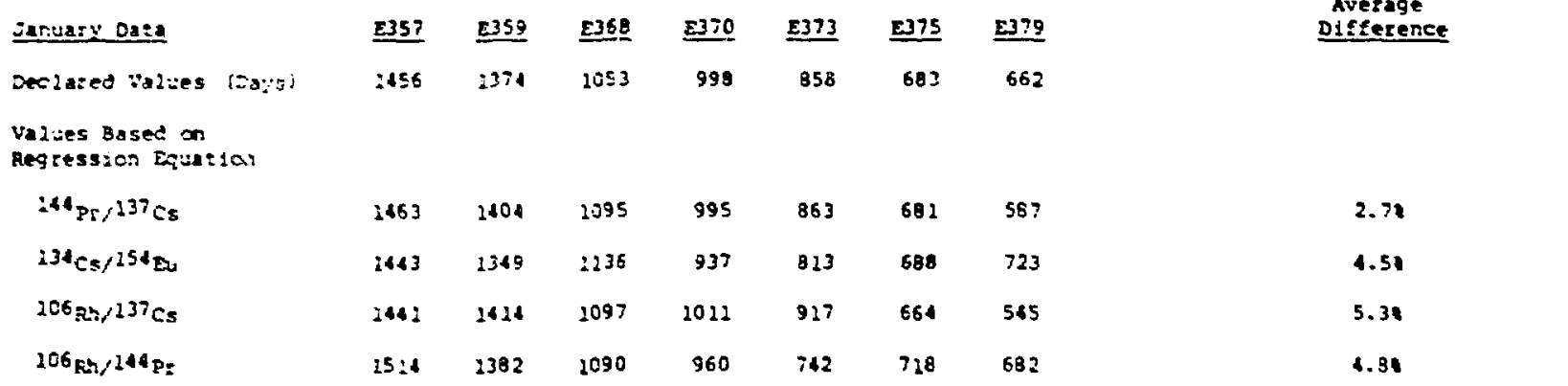


STANDARO DEVIATTONS OF $\left(\hat{t}_{c}-t_{c}\right)$ BY USING THE AVERAGE $\ln \left(\lambda_{0}\right)$ and $\ln \left(A_{02} / A_{O 1}\right)$ valuEs

$\begin{array}{ccc}\text { Isctope } & \begin{array}{c}\text { Number of } \\ \text { Samples in Set }\end{array} & \text { Standerd Deviation of }\left(\hat{t}_{c}-t_{c}\right) \\ 134 \mathrm{Cs}(605 \mathrm{keV}) & 10 & \pm 114 \text { days } \\ & 10 & \pm 133 \text { days } \\ 106 \mathrm{Rh}(1050 \mathrm{keV}) & 5 & \pm 110 \text { days } \\ & 10 & \pm 129 \text { days } \\ 114 \mathrm{Pr}(1487 \mathrm{keV}) & 5 & \pm 74 \text { days } \\ & 586 \text { days }\end{array}$

Ratio

$\begin{array}{lcc}144 \mathrm{Pr} / 137 \mathrm{Cs} & 10 & \pm 11 \text { days } \\ 134 \mathrm{Cs} / 154_{\mathrm{Eu}} & 5 & \pm 18 \text { days } \\ & 10 & \pm 82 \text { days } \\ 106 \mathrm{Rh} / 137 \mathrm{Cs} & 5 & \pm 94 \text { days } \\ & 10 & \pm 60 \text { days } \\ 106_{\mathrm{Rh} / 114} \mathrm{Pr} & 5 & \pm 69 \text { days } \\ & 10 & \pm 99 \text { days } \\ & 5 & \pm 114 \text { days }\end{array}$

\section{Linear Model}

This model relates the cooling times with the measured iso'copic activities and ratios with

$$
t_{c}=a+b\left(A_{i} \text { or } A_{i} / A_{j}\right)
$$

where $t_{c}$ was the cooling time, $A_{i}$ and $A_{i} / A_{j}$ were the measured activities of the $i$ th and $j$ th isotopes, and $a$ and $b$ were the parameters of the regression equation. As was discussed earlier this relationship can be' a good approximation when $\lambda t_{c}$ and $\left.a_{1}-\lambda_{2}\right) t_{c}$ are small. This model is the simplest of the two models discussed and is easy to apply provided the above conditions can be assumed to exist. 
Principal component analysis indicated that cver 85 of the variation in the September data was confined to a two-dimensional space. By increasing the dimensions to three, 948 of the variation was explained. In the January data more than 958 of the yeriation in the predictor variable is confined to a tivodimensional space. From these analyses there appear to be two or three independent sources of variations in the data. Based upon this we would hope to find two or three relatively independent groups of predic: rr variables among the set of 33 variables that contain most of the available information concerning cooling time.

cluster analysis was used as an exploratory technique to see if there were subgroups of variables that appeared in both September and January data sets. For both the September and January data four distinct groups of variables appeared in the set of 33 variables. The four clusters are listed in Table V. The ${ }^{134} \mathrm{Cs}(605 \mathrm{keV}) /{ }^{137} \mathrm{Cs}(662 \mathrm{keV})$ (Cluster I) and the ${ }^{154} \mathrm{Eu}(1275$ $\mathrm{keV}) /{ }^{144} \mathrm{Pr}(2186 \mathrm{keV})$ (Cluster IV) isotopic ratios seemed to do a very good job of explaining cooling time variation in both exercises.

The ${ }^{134} \mathrm{Cs}(605 \mathrm{kev}) /{ }^{137} \mathrm{Cs}(662 \mathrm{keV})$ isotopic ratio explained 91.48 of the variation in cooling times for the September data (Fig. 5) and 92.98 for the January data (Fig. 6). On each of the plots, the 958 confidence bounds are shown. These bounds may be interpreted as defining a region within which one is 958 confident that the individual cooling time value will fall for a measured ratio value. The width of these bounds depends upon several factors. Two factors that cannot be controlled by the experimenter are the values of the ratic at which one wishes to estimate the cooling time and the values of the standard deviations of cooling time for a fixed ratio (the bounds become wider as this quantity increases). Two other factors that can be controlled by the experimenter to some extent are the spread of the ratio values used in the least-squares analysis and the number of elements used. The width of the confidence bounds decreases as either the spread of ratios or number of elemants used increases.

Similarly, the values for the ${ }^{154} \mathrm{Eu}(1275 \mathrm{keV}) /{ }^{144} \mathrm{Pr}(21.86 \mathrm{keV})$ explained 95.58 and $96.8 \AA$ of the variations for the September data (Fig. T) and January data (Fig. 8), respectively. Table VI shows these results fur individual fuel elements, plus the results of a linear combination of these two ratios which explained over 998 of the variations in each of the data sets. The January results have been calculated twice: once with element E374 


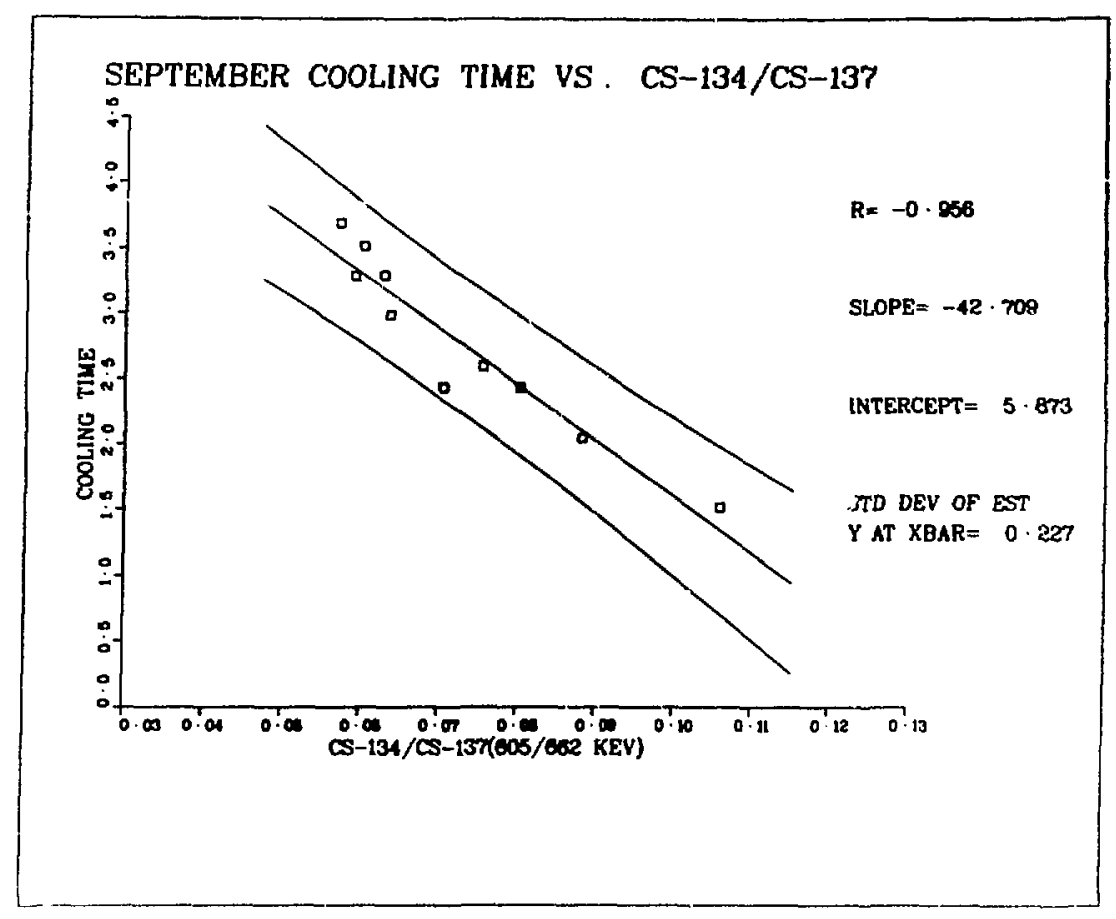

Fig. 5.

Plot of cooling time in years versus the ${ }^{134} \mathrm{Cs}(605 \mathrm{keV}) / 137 \mathrm{Cs}(662 \mathrm{keV})$ isotopic ratio for the September data.

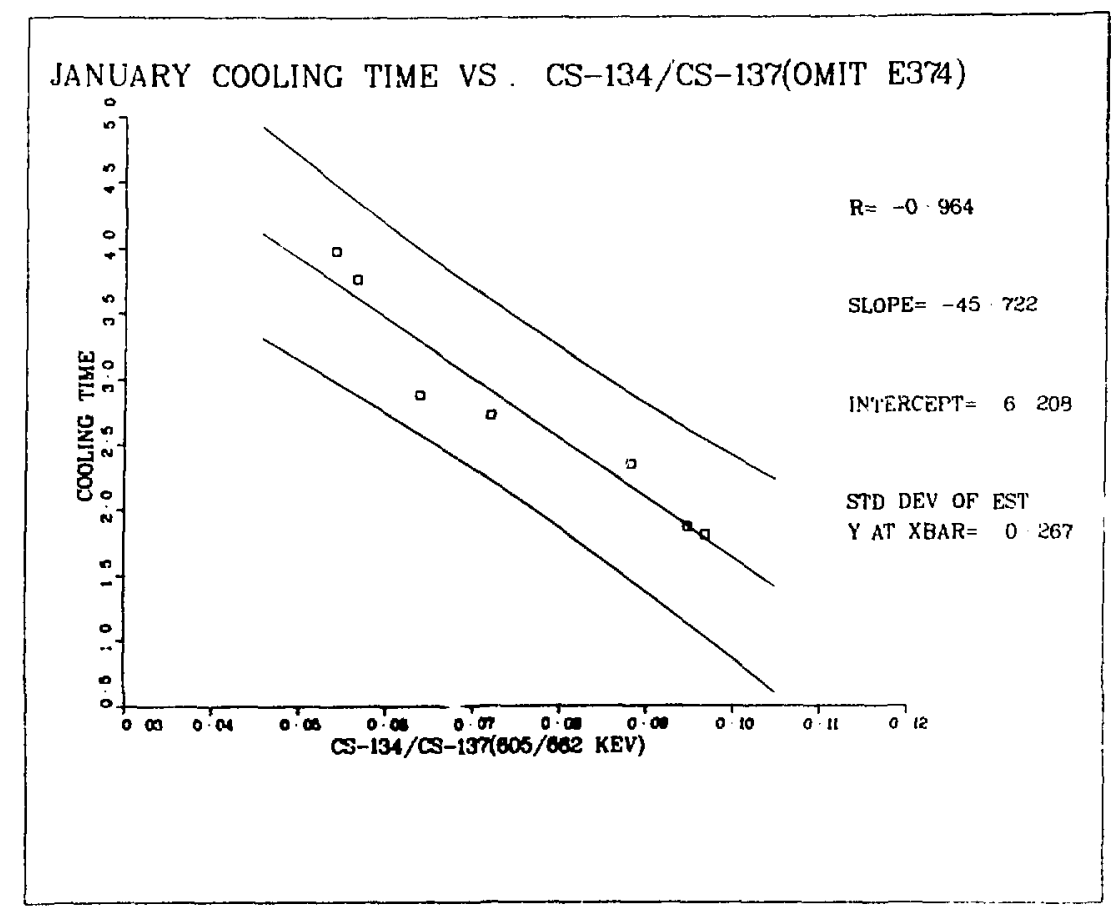

The cooling time with respect to the ${ }^{134} \mathrm{Cs}(605 \mathrm{keV}) / 137 \mathrm{Cs}(662 \mathrm{keV})$ isotopic ratio is shown for the January data. 


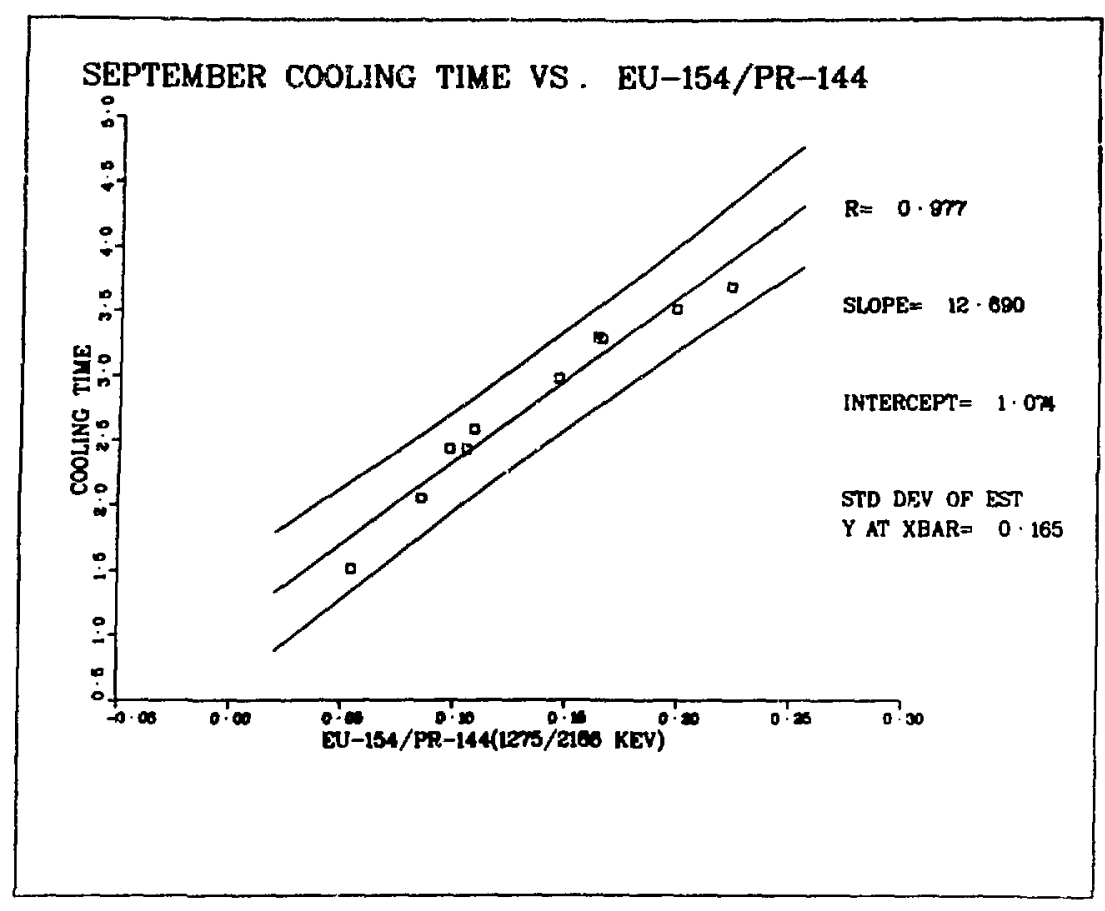

Fig. 7 .

Linear least squares fit of cooling time with respect to the ${ }^{154} \mathrm{Eu}(1275 \mathrm{keV}) /$ ${ }_{144} \mathrm{Pr}(2186 \mathrm{keV})$ isotopic ratios for the September data.

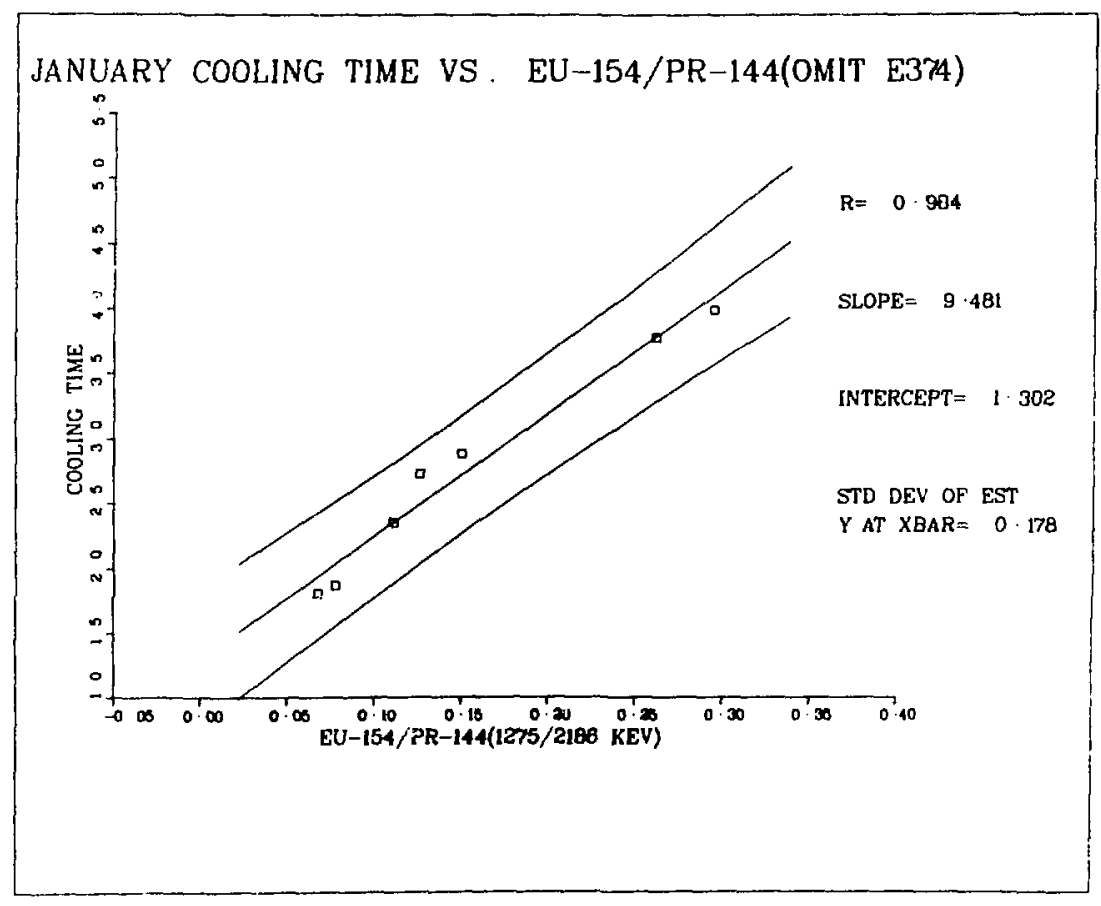

Fig. 8 .

Linear least squares fit of cooling time with respect to the ${ }^{154} \mathrm{Eu}(1275 \mathrm{keV}) /$ $144 \operatorname{Pr}(2186 \mathrm{keV})$ isotopic ratios for the January data. 
TRBLE V

CLUSTERS FOR SELECTION OF COOLING TIME VARIABLES - MODEL (2)

\section{Cluster I}

${ }^{134} \mathrm{Cs}(605 \mathrm{keV})$

${ }^{134} \mathrm{Cs}(796 \mathrm{keV})$

${ }^{134} \mathrm{Cs}(1038 \mathrm{keV})$

${ }^{134} \mathrm{Cs}(1365 \mathrm{keV})$

${ }^{134} \mathrm{Cs}(605) /{ }^{137} \mathrm{Cs}(662)$

${ }^{134} \mathrm{Cs}(796) /{ }^{137} \mathrm{Cs}(662)$

${ }^{134} \mathrm{Cs}(1038) /{ }^{137} \mathrm{Cs}(662)$

${ }^{134} \mathrm{Cs}(1365) /{ }^{137} \mathrm{Cs}(662)$

${ }^{106} \mathrm{Rh}(1050 \mathrm{keV})$

${ }^{144} \operatorname{Pr}(696 \mathrm{keV})$

${ }^{144} \operatorname{Pr}$ (1487 $\mathrm{keV}$ )

${ }^{144} \operatorname{Pr}(2186 \mathrm{keV})$
Cluster II

${ }^{137} \mathrm{Cs}(662 \mathrm{keV})$

154

${ }^{154} \mathrm{Eu}(1005 \mathrm{keV})$
${ }_{154} \mathrm{Eu}(1275 \mathrm{keV})$

${ }^{154} \mathrm{Eu}(1275) /{ }^{137} \mathrm{Cs}(662)$
Cluster IV

${ }^{134} \mathrm{Cs}(605) /^{144} \operatorname{Pr}(696)$

${ }^{134} \mathrm{Cs}(796) / 144 \operatorname{Pr}(696)$

${ }^{134} \mathrm{Cs}(796) /{ }^{14} \operatorname{Pr}(2186)$

${ }^{134} \mathrm{Cs}(1365) / 144 \operatorname{Pr}(2186)$

${ }^{134} \mathrm{CB}(796) /{ }^{106} \mathrm{Rh}(1050)$

${ }^{154} \mathrm{Eu}(1005) /{ }^{106} \mathrm{Rh}$ (1050)

${ }^{154} \mathrm{Eu}(1275) /{ }^{106} \mathrm{Rh}$ (1050)

${ }^{154}$ Eu (1005)/144 $\operatorname{Pr}$ (1487)

${ }^{154} \mathrm{Eu}(1275) /{ }^{144} \mathrm{Pr}(1487)$

${ }^{154} \mathrm{Eu}(1275) /{ }^{144} \operatorname{Pr}(2186)$

included in the data and once without. All of the elements had irregular irradiation exposures as indicated by Fig. 1, however, the history of E374 was very different from the other elements. It was irradiated for 707 days, then removed from the core and allowed to cool for 313 days. It was then rejrradiated for another 246 days. Therefore, the January results presented in Table VI do not include the E374 element in the analysis.

Comparison of the Two Models for Estimating Relative Cooling Times

In both of the models evaluated various assumptions have to be accepted prior to their application to the fuel assemblies examined. We have assumed that each fuel assembly has been exposed to a similar irradiation history. This assumption is critical in each of the models. As discussed in the last two sections this was illusirated by including the results for element E374 which had a significantly different irradiation history. 
TABLE VI

COOLING TIME RESULTS BASED ON ${ }^{134} \mathrm{Cs} / /^{137} \mathrm{CS}$ NND ${ }^{154} \mathrm{Eu} / /^{144} \mathrm{pX}$ RATIOS - MONEL (2)

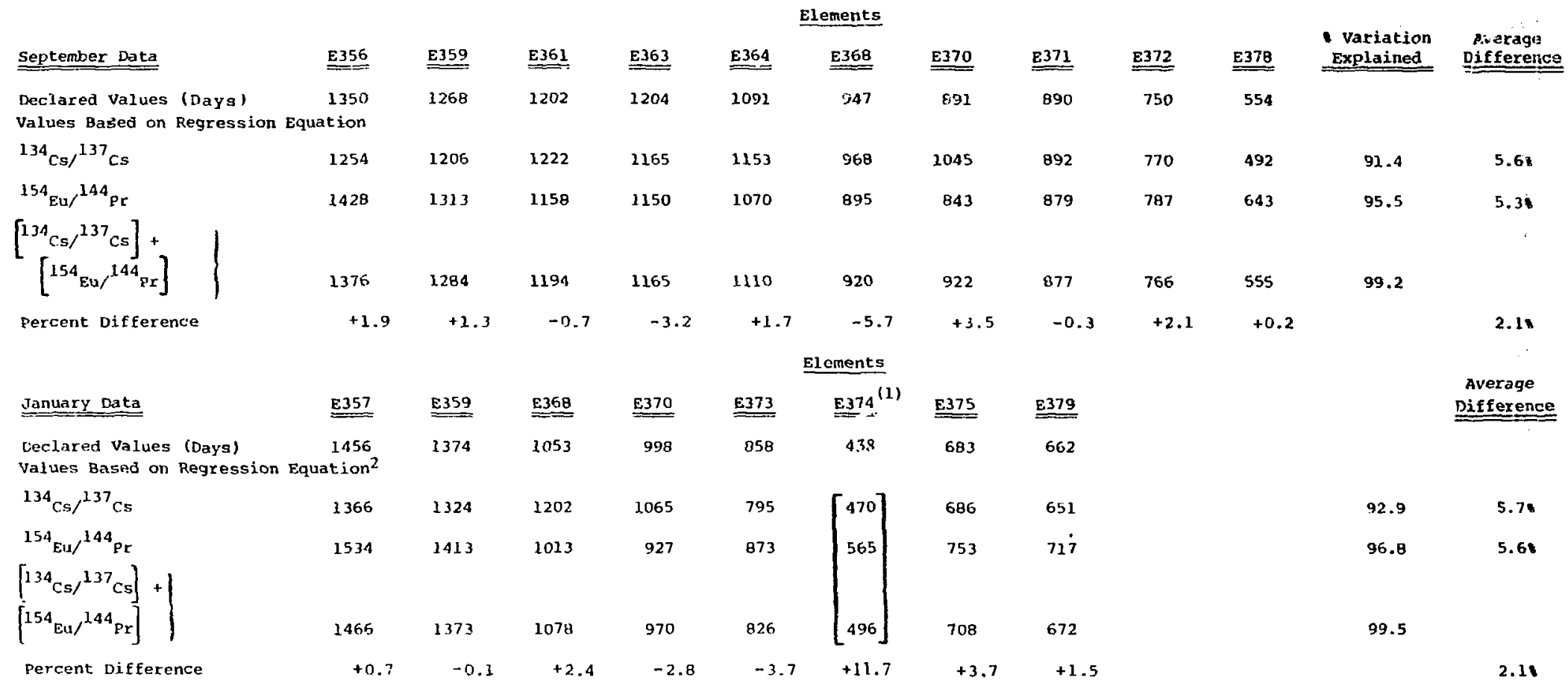

1 E374 was irradiated for 707 days, then cooled for 313 days before being irradiated another 246 days. This result wa: declared an outlier and was not included in the remaining analysis.

2 values computed from data set excluding F.374. 
Either the nonlinear or the linear model can be used to predict the consistency of relative cooling times with a precision of 1 to 6 relative percent. The nonlinear model (1) generally gives slightly better predictions than the linear model because the required condition that $\lambda_{c}$ and $\left.a_{1} \lambda_{2}\right) t_{c}$ must be small is not satisfied for all assemblies. For the cooling times we examined, the ${ }^{144} \mathrm{Pr}$ isotope appears as the best single isotope predictor as well as being a component of most of the ratios and linear combinations. This may be explained by two reasons. First, the half-life of ${ }^{144} \operatorname{pr}(284.4 d)$ is comparable to the cooling times of these sets of fuel assemblies, and secondly, the two gamma-ray peaks at 1487 and $2186 \mathrm{keV}$ were measured very precisely because of their relative activities.

In applying either of these models, the experimenter must be cautious because of the effect that irradiation histories can have upon the results. This is particularly true when ${ }^{134} \mathrm{Cs}$ and ${ }^{154} \mathrm{Eu}$ occur in the ratios which predict the cooling times in both the nonlinear and linear models. Both of these isotopes can be produced by one or more neutron captures of the fission products which are very dependent upon irradiation precursor histories. The contribution of ${ }^{134} \mathrm{Cs}$ and ${ }^{154} \mathrm{Eu}$ should be a function of the integrated flux that the assemblies had been exposed to during irradiation. The functional relationship of these two isotopes with respect to the flux will be discussed further in the section on Axial Profile Measurements.

IV. BURNUP MEASITREMENTS

The gamma-iay results for the fission products were corrected for the declared cooling time, and then analyzed to determine which variable or set of variables provided the best prediction of burnup values. All of the burnup calculations were based upon the total number of grams ${ }^{235} \mathrm{U}$ fissioned. Because of the experimental arrangement, the entire fuel element was examined. The initial ${ }^{235} \mathrm{v}$ loading of individual fuel elements varied from 216 to 224 grams, and the operator-declared grams of ${ }^{235} \mathrm{U}$ fissioned ranged from 61 to 74 grams.

Prircipal component analysis showed that in the September data over 798 of the variation in the predictor variables was confined to a two-dimensjonal space. By increasing the dimensions to three, alnust 88 of the variation was explained. However, over $92 \%$ of the variation in the January data was confined to a two-dimensional space. There appears to be considerably more variation in 
the septeraber data than in the January data. Perhaps for this reason, fewer varfables could be identified as falling in well-defined groups in both exercises. Table VII shows three groups that did appear in each exercise. The ${ }^{154} \mathrm{Eu}(1275 \mathrm{keV}) /^{144} \mathrm{Pr}(2186 \mathrm{keV})$ and ${ }^{134} \mathrm{Cs}(796 \mathrm{keV}) /{ }^{137} \mathrm{Cs} \quad(662 \mathrm{keV})$ isotopic ratios and ${ }^{137} \mathrm{Cs}(662 \mathrm{keV})$ did not fall in any specific groups that were Identiflable in both the September and January exercises. Four variables, ${ }^{137} \mathrm{Cs}\left(662 \mathrm{keV},{ }^{134} \mathrm{Cs}(605 \mathrm{keV}) /{ }^{137} \mathrm{Cs}(662 \mathrm{keV}),{ }^{134} \mathrm{Cs}(796 \mathrm{keV}) /{ }^{137} \mathrm{Cs}(662\right.$ $\mathrm{keV}$, and ${ }^{154} \mathrm{Eu}(1275 \mathrm{keV}) /{ }^{137} \mathrm{Cs}(662 \mathrm{keV})$ were determined to be among the most important predictors of relative burnup values, when considering both exercises.

The measured results for the relative burnup values are shown in Table VIII in which the September and January data are separated. In each exercise the burnup results were computed based upon the ${ }^{137} \mathrm{Cs}(662 \mathrm{keV}),{ }^{134} \mathrm{Cs}$ $(605 \mathrm{keV}) /{ }^{137} \mathrm{Cs} \quad(662 \mathrm{keV}),{ }^{134} \mathrm{Cs} \quad(796 \mathrm{keV}) /{ }^{137} \mathrm{Cs} \quad(662 \mathrm{keV})$, and ${ }^{154} \mathrm{Eu}$ $(1275 \mathrm{keV}) / 137 \mathrm{Cs}(662 \mathrm{keV})$ values. of these four values, the ${ }^{137} \mathrm{Cs}$ $(796 \mathrm{keV}) /{ }^{137} \mathrm{Cs}(662 \mathrm{keV})$ ratio explained most of the variation $(70.48)$ in the September exercise. The best two variable linear combinations 172.48 of

\section{TABLE VII}

GROUPS OF PREDICTORS OF BURNUP FOR DATA CORRECTED FOR COOLING TIME

\section{Cluster I}

${ }^{134} \mathrm{Cs}(605) /{ }^{144} \operatorname{Pr}(696)$

${ }^{134} \mathrm{Cs}(796) /{ }^{144} \operatorname{Pr}(696)$

${ }^{134} \mathrm{Cs}_{5}(796) /{ }^{144} \operatorname{Pr}(2186)$

${ }^{134} \mathrm{Cs}(1365) / 144 \operatorname{Pr}(2186)$

${ }^{134} \mathrm{Cs}(796) /{ }^{106}{ }_{R h}(1050)$

${ }^{134} \mathrm{Cs}(1038) /{ }^{106} \mathrm{Rh}$ (1050)

${ }^{154} \mathrm{Eu}(1005) /{ }^{144} \operatorname{Pr}(1487)$

${ }^{154} \mathrm{Eu}(1275) /{ }^{144} \operatorname{Pr}(1487)$

${ }^{154} \mathrm{Eu}(1275) /{ }^{144} \operatorname{Pr}(2186)$

${ }^{154} \mathrm{Eu}(1275),{ }^{, 106} \mathrm{Rh}(1050)$
Cluster II

${ }^{134} \mathrm{cs}(605 \mathrm{keV})$

${ }^{134} \mathrm{Cs}(605) / 137 \mathrm{Cs}(662)$
Cluster III

${ }^{106} \mathrm{Rh}(1050 \mathrm{keV})$

${ }^{144} \operatorname{Pr}(1487 \mathrm{keV})$

${ }^{144} \mathrm{Fr}(2186 \mathrm{keV})$ 
TABLE VIII

SONSISTENCY OF CALCULATED BURNUP VRLUES BASED UPQN DECLARED COOLING TIMES

Element Identification

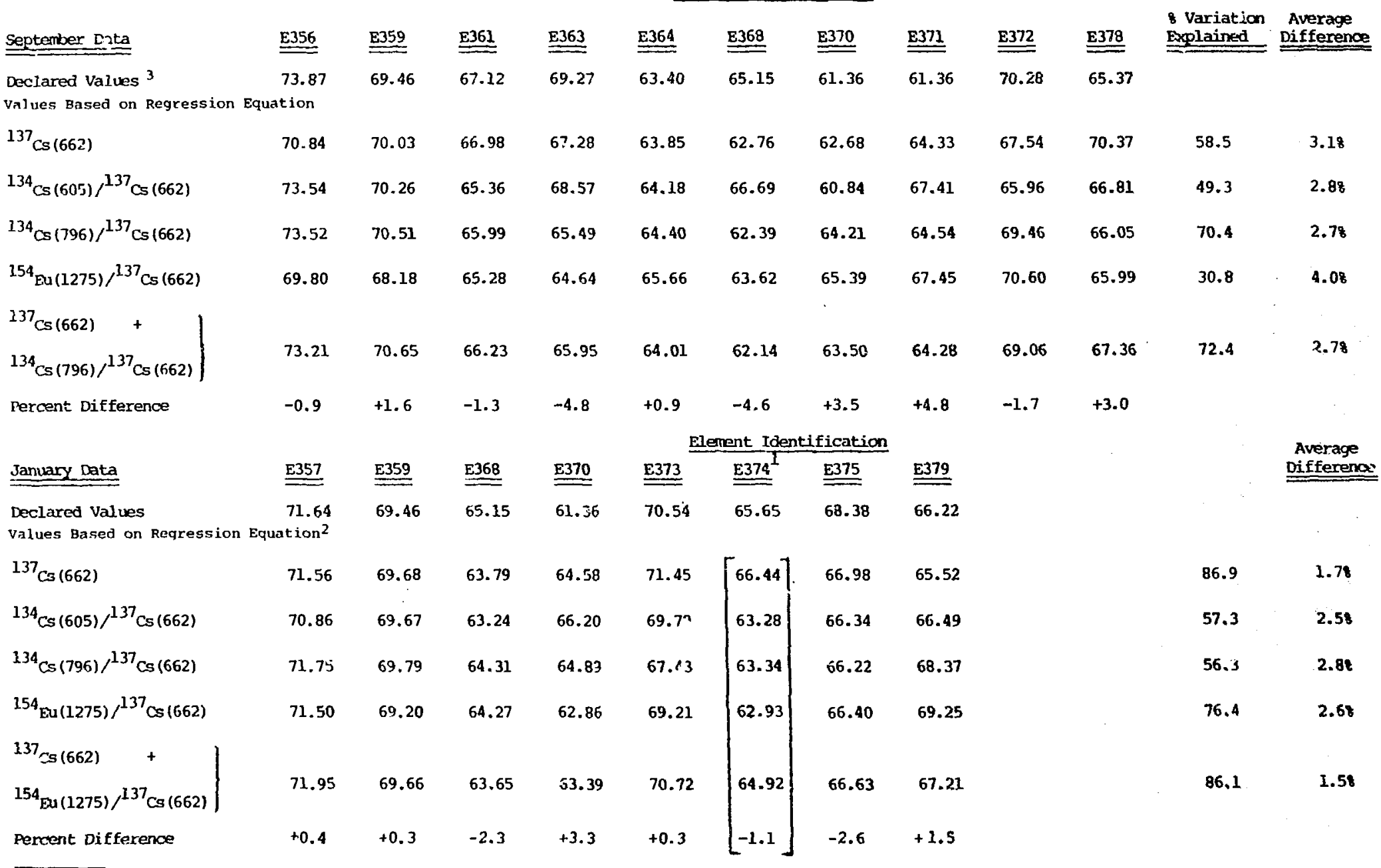

Eletient E374 nesults are based upon the data including E374 data in analysis.

2 Measured values are based upon seven elements, with E374 excludied because of irregular irradiation exposure.

$3_{\text {Bumup values axe expressed in grams }} 235 \mathrm{U}$. 
the variation) for september were the ${ }^{137} \mathrm{Cs}\left(662 \mathrm{keV}\right.$ ) and ${ }^{134} \mathrm{Cs}(796 \mathrm{keV} /$ ${ }^{137} \mathrm{Cs}(662 \mathrm{keV})$ with the ${ }^{134} \mathrm{Cs} /{ }^{137} \mathrm{Cs}$ being the dominant term. An average absolute percentage difference of 2.78 between the declared and predicted values was obtained in this data set. By increasing the number input parameters to include all four measured values, the percent variation explained increased from 72.48 to 80.38. Plots of these four parameters versus the declared burnup values are presented in Figs. 9-12 with the $95 \%$ confidence bounds plotted. The qualifying statements discussed in the cooling time results section are also applicable to these results.

The results for the January data (Figs. 13-16) are presented in Table VIII and are similar to those obtained in the september exercise except that the linear combination of ${ }^{137} \mathrm{Cs}(662 \mathrm{keV})$ and ${ }^{154} \mathrm{Eu}(1275) /{ }^{137} \mathrm{Cs}$ (662) provided the best correlations. Both the ${ }^{137} \mathrm{Cs}(662 \mathrm{keV})$ by itself and the linear combination explained about 868 of the variations in the declared burnup values. The results for element E374 were excluded because of its irregular irradiation history (discussed in the section on cooling times). In this particular exercise there is not any advantage in extending the analysis to include more than two variables. However, if all four variables are included, the percent variation explained significantly increases to 94.38 (Table IX).

There are three basic assumptions necessary in evaluating the results using the above analysis techniques. First, the relationship between the isotopic ratios and grams of ${ }^{235} \mathrm{v}$ burnup is linear. This allows the estimation of error based on the deviations from a straight-line fit. Second, the distribution of deviations about the straight line is assumea to be Gaussian with zero mean and constant standard deviation. Third, the variance of the measured ratios due to the measuring statistics are insignificant.

The agreement between the predicted values and the declared values for the burnup of individual assemblies was very good. However, these correlations demonstrate a consistency between the two values and still require some irradiation history information to allow the independent verification of the declared burnup values. 


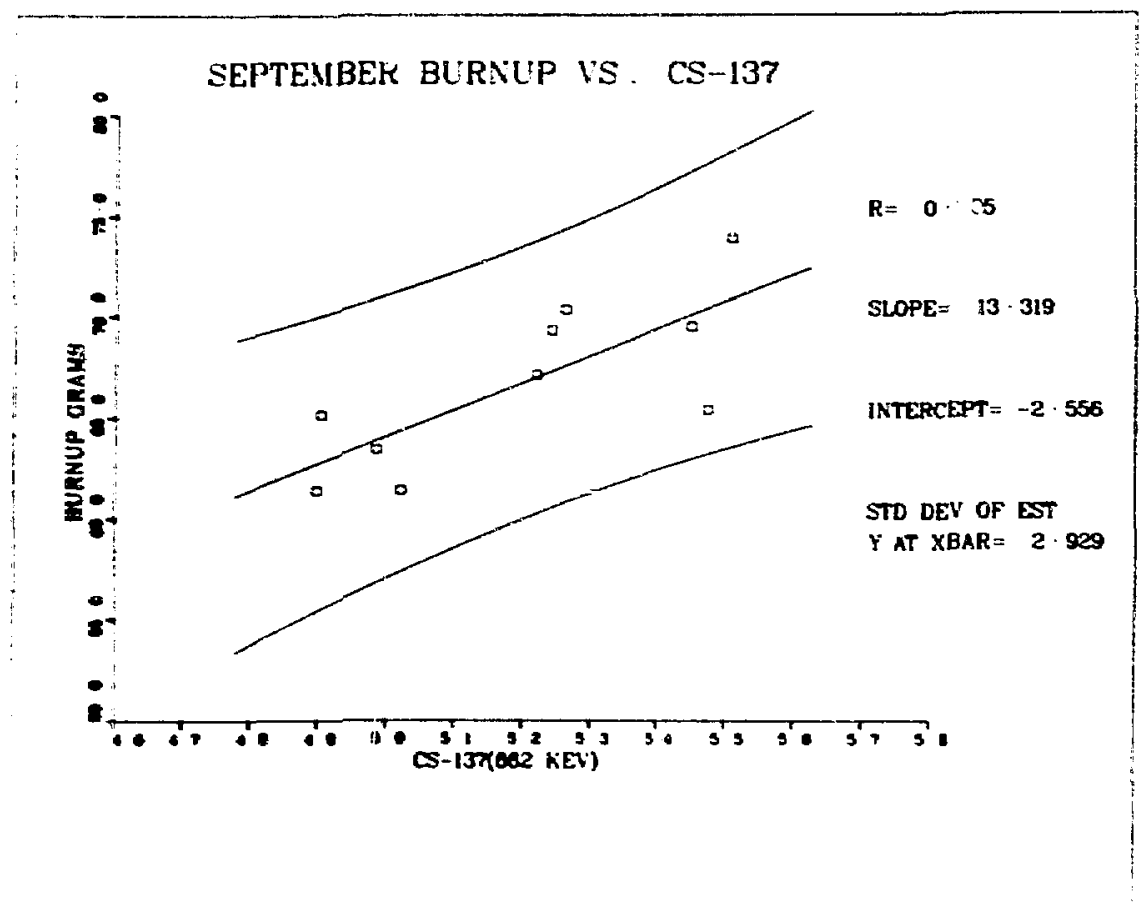

Fig. 9.

The linear relationship of declared burnup in grams with respect to ${ }^{137} \mathrm{Cs}$ (662 keV) activity for the september data.

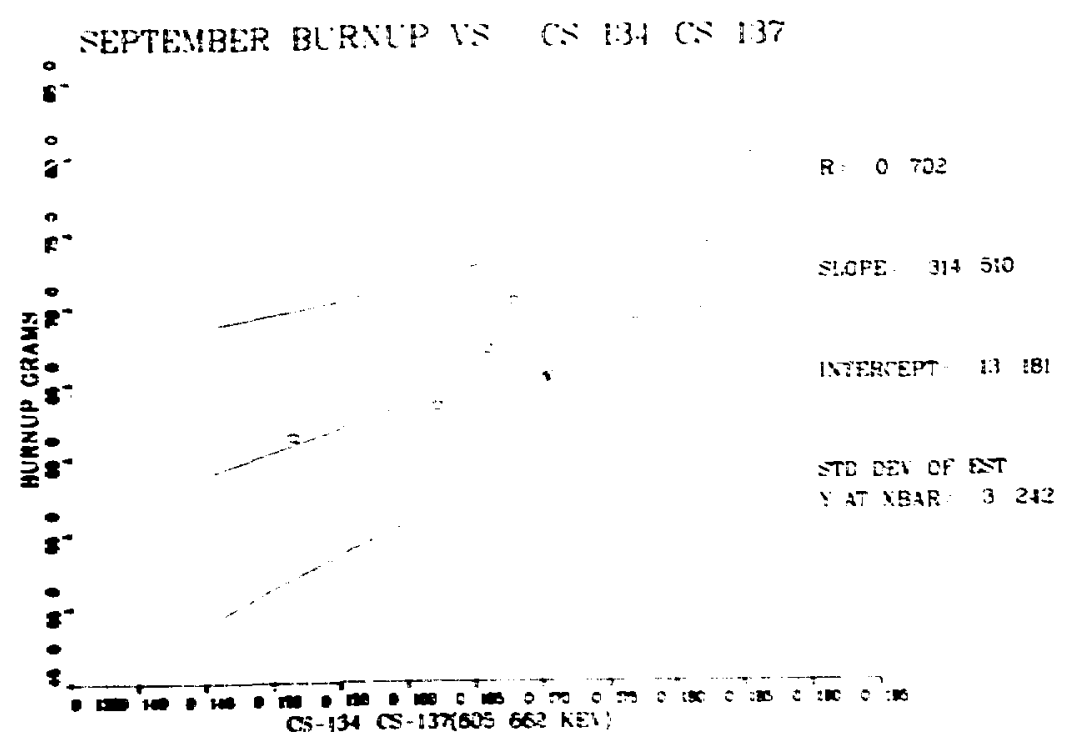

Fig. 10 .

The linear relationship of declared burnup in qrams with respect to $134 \mathrm{Cs}$ $(605 \mathrm{keV}) / 137 \mathrm{Cs}(652 \mathrm{keV})$ isotopic ratio. 


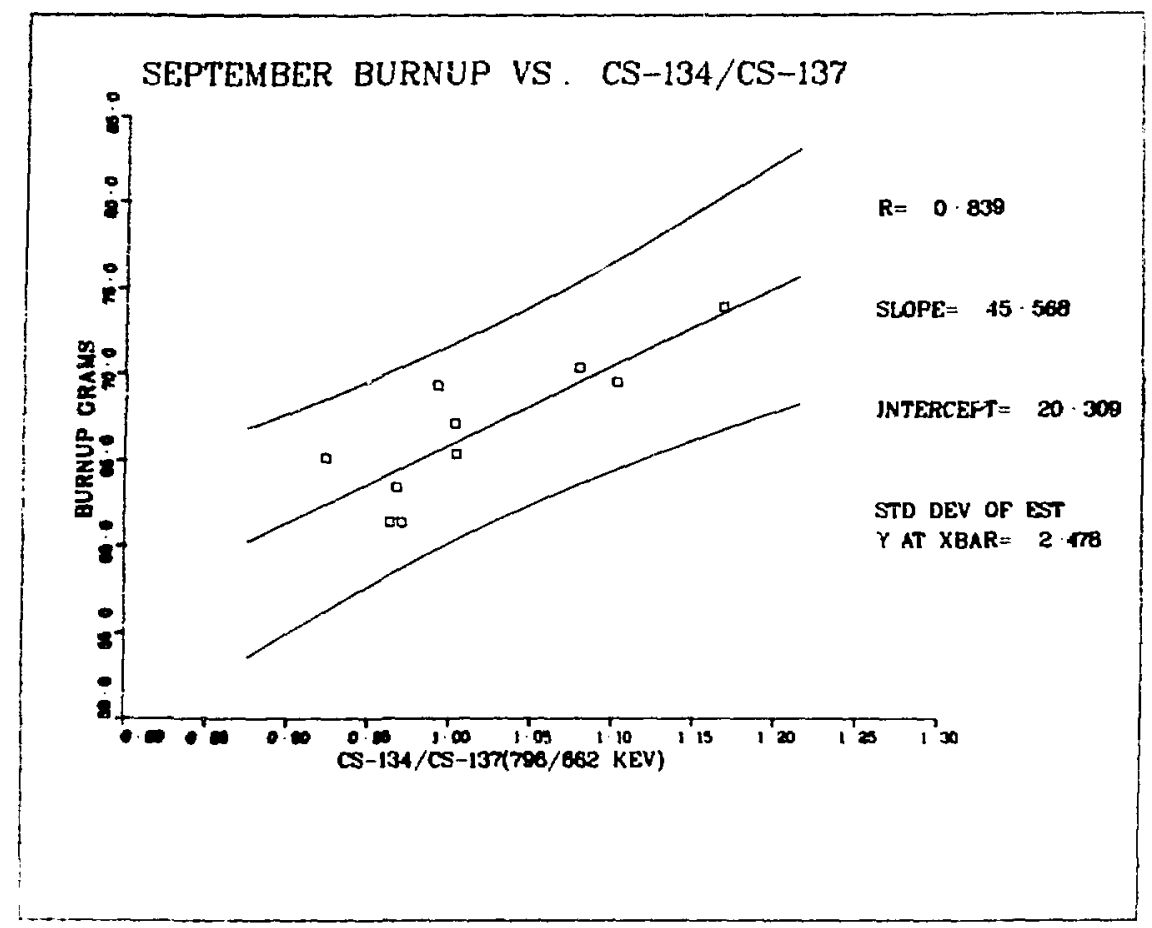

Fig. 11.

The linear relationship of declared burnup in grams with respect to $134 \mathrm{Cs}$ $(796 \mathrm{kev}) / 137 \mathrm{Cs}(662 \mathrm{keV})$ isotopic ratio.

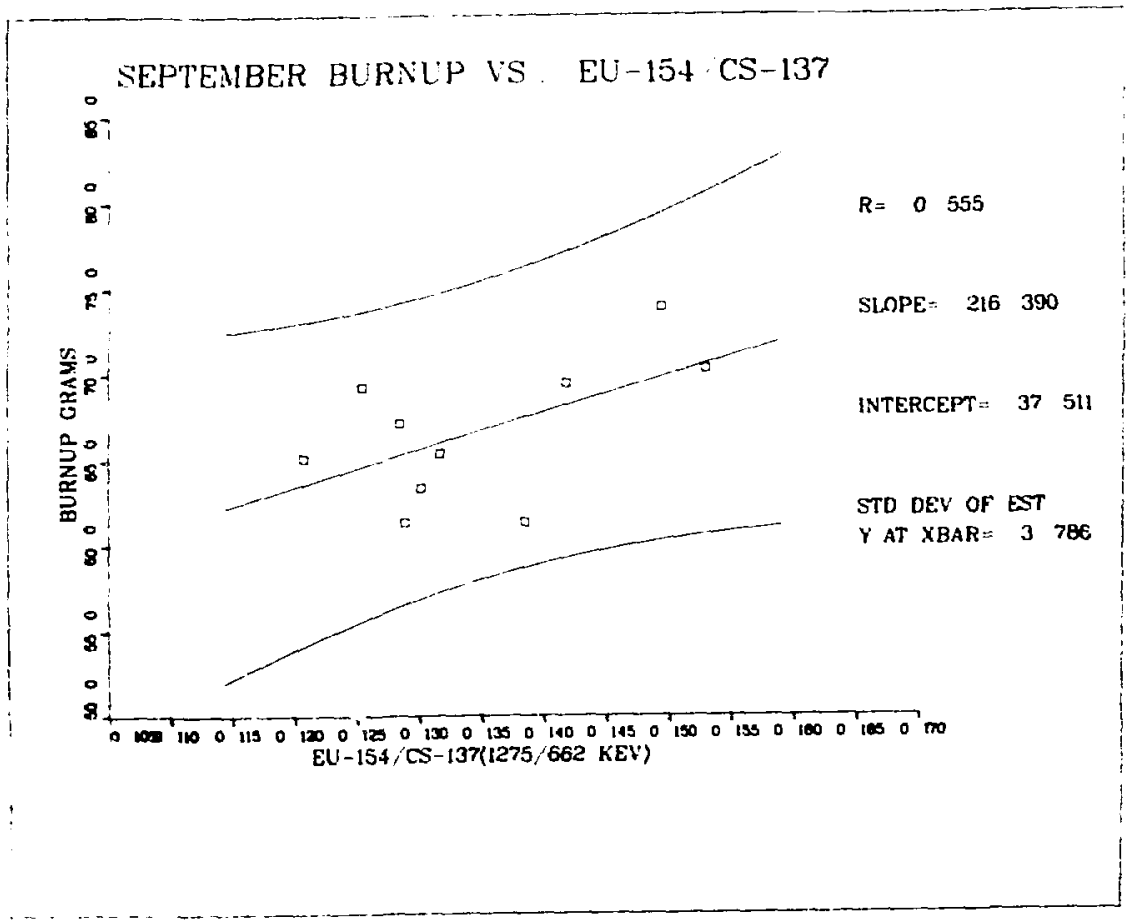

Fig. 12 .

The linear relationship of declared burnup in grams wits respect to $154 \mathrm{Eu}$ $(1275 \mathrm{keV}) / 137 \mathrm{Cs}(662 \mathrm{keV})$ isotopic ratio. 


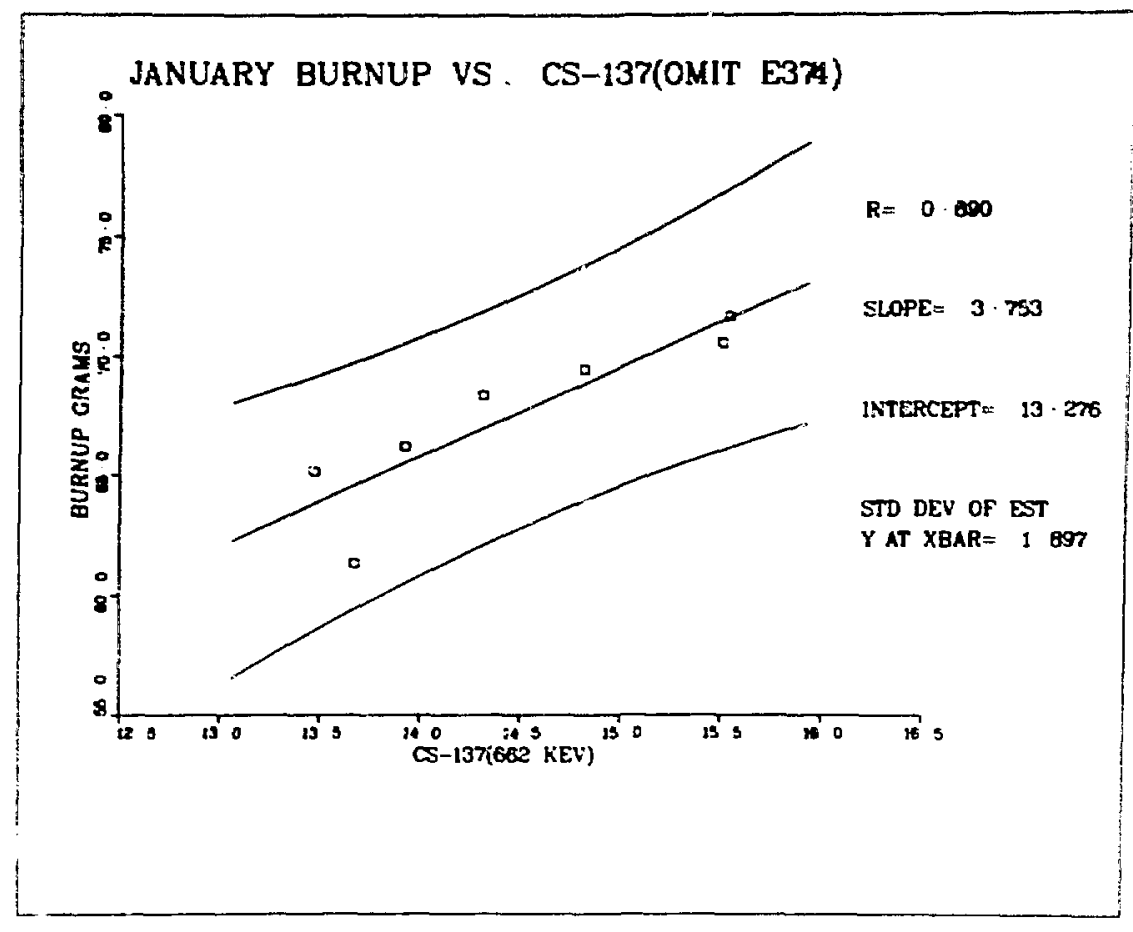

Fig. 13.

The linear relationship of declared burnup in grams with respect to $137 \mathrm{Cs}$ $(662 \mathrm{keV})$ activity for the January data.

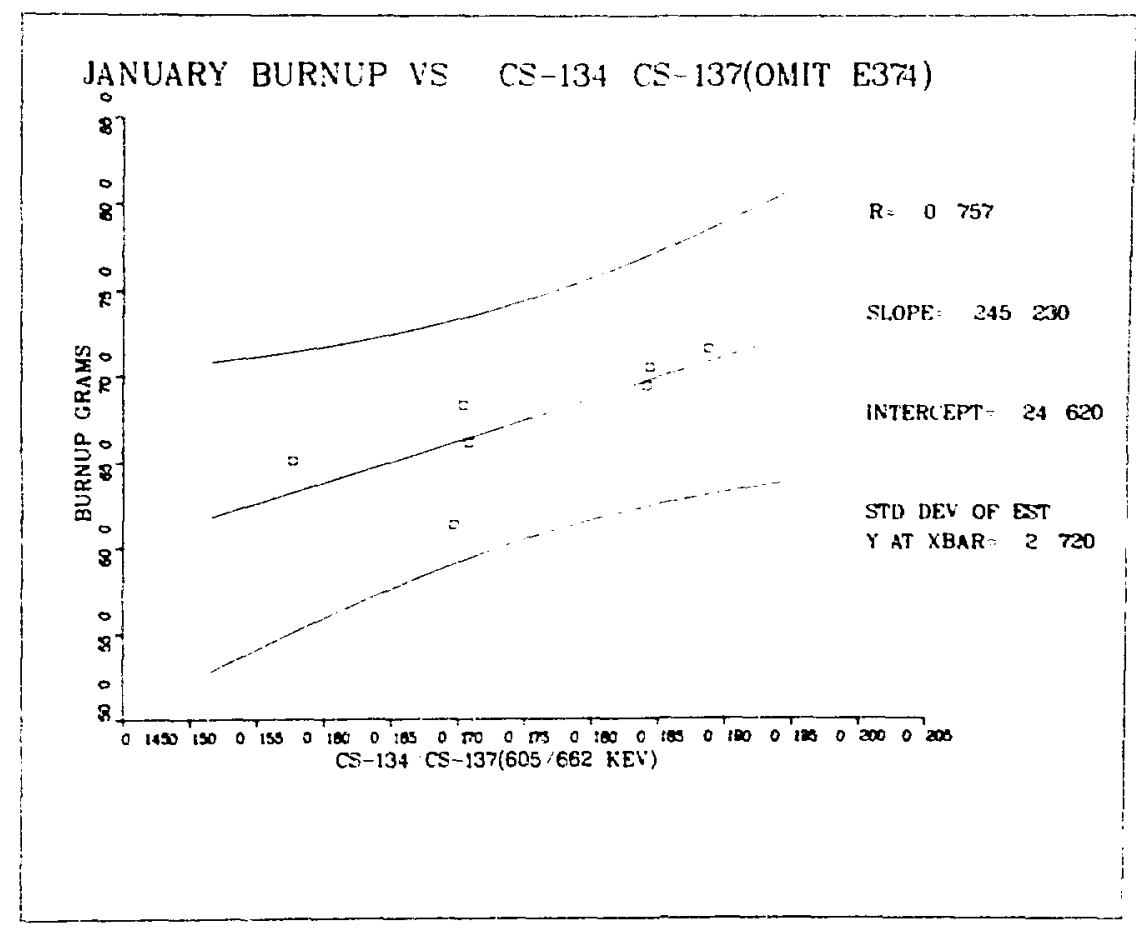

Fig. 14.

The linear relationship of declared burnup in qrams with respect to $134 \mathrm{Cs}$ $(605 \mathrm{keV}) / 137 \mathrm{Cs}(662 \mathrm{keV})$ isotopic ratio. 


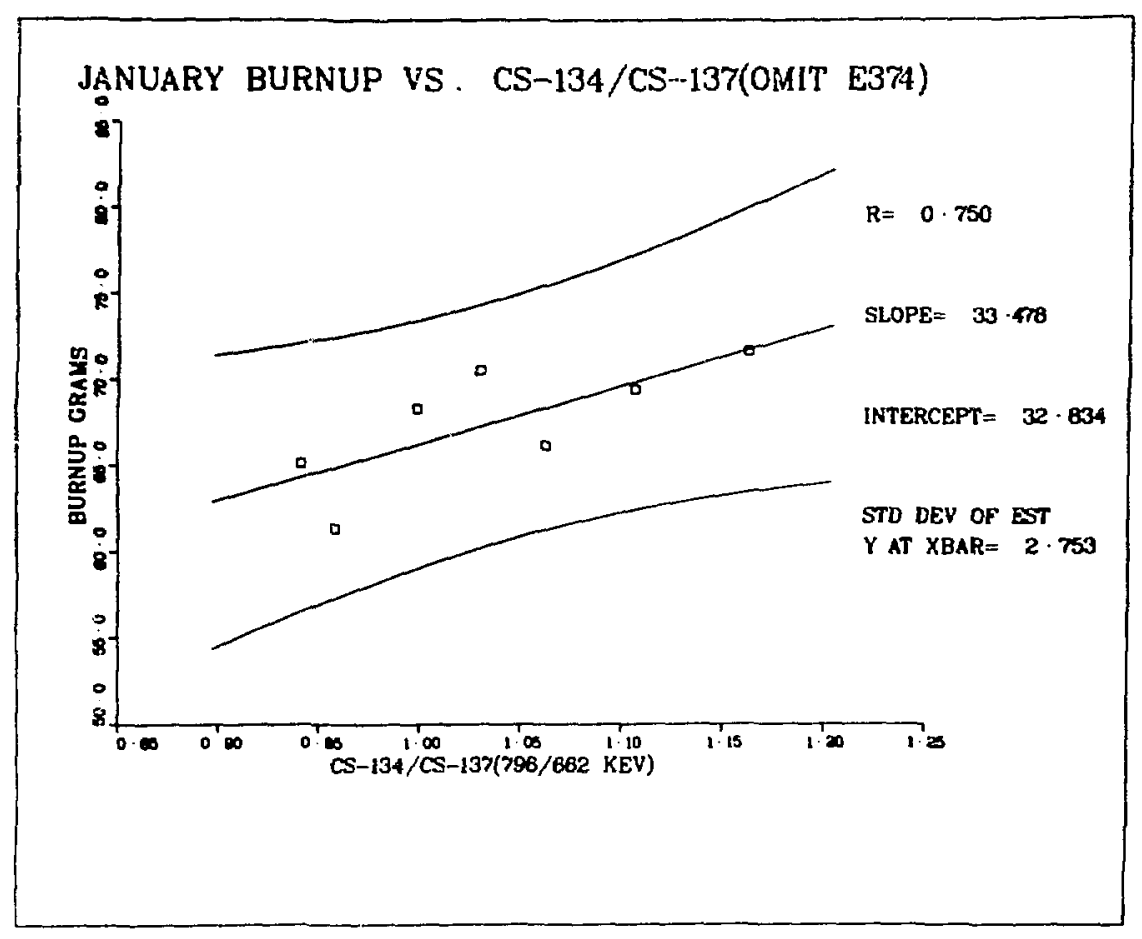

Fiq. 15.

The linear relationship of declared burnup in grams with respect to $134 \mathrm{Cs}$ $(796 \mathrm{keV}) / 137 \mathrm{Cs}(662 \mathrm{keV})$ isotopic ratio.

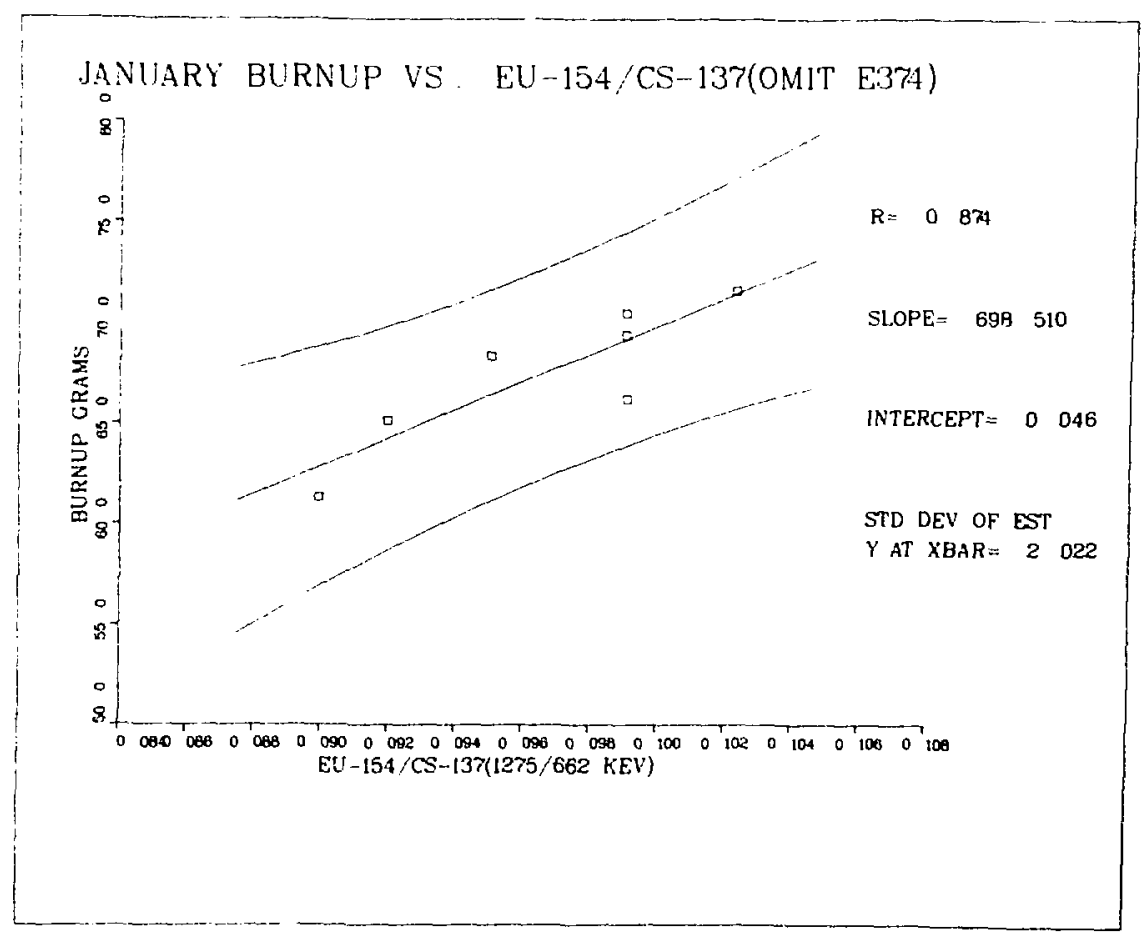

Fig. 16.

The linear relationship of declared burnup in grams with respect to ${ }^{154} \mathrm{Eu}$ $(1275 \mathrm{keV}) / 137 \mathrm{Cs}(662 \mathrm{keV})$ isotopic ratio. 
TABLE IX

CONSISTENCY OF CALCULATFN BURNUP VALUES BASED UPON FOUR PARMMETERS

\begin{tabular}{|c|c|c|c|c|c|c|c|c|c|c|c|c|}
\hline \multirow[b]{2}{*}{ Scptember Data } & \multicolumn{10}{|c|}{ Element Identiflcation } & \multirow[b]{2}{*}{$\begin{array}{l}\text { Variation } \\
\text { Explained }\end{array}$} & \multirow[b]{2}{*}{$\begin{array}{c}\text { Average } \\
\text { Difference }\end{array}$} \\
\hline & E.356 & $\underline{E 359}$ & E361 & E363 & E364 & $\underline{E 368}$ & $\underline{E 370}$ & $\underline{E 371}$ & $\underline{E} 372$ & $E 378$ & & \\
\hline Declated value ${ }^{3}$ & 73.87 & 69.46 & 67.12 & 69.27 & 53.40 & 65.15 & 61.36 & 61.36 & 70.28 & 65.37 & & \\
\hline $\begin{array}{l}\text { Values Based on } \\
\text { Regression Equat }\end{array}$ & $\begin{array}{l}74.11 \\
\text { on }\end{array}$ & 71.43 & 66.33 & 67.20 & 63.81 & 63.63 & 62.73 & 63.70 & 67.04 & 66.13 & 80.3 & 2.25 \\
\hline Difference & +0.3 & +2.8 & -1.2 & -3.0 & +0.7 & -2.3 & $=2.2$ & +3.8 & -4.6 & +1.2 & & \\
\hline \multicolumn{13}{|c|}{ Element Identification } \\
\hline January Data & E357 & E359 & E368 & E370 & E373 & E374 ${ }^{1}$ & $\mathbf{E 3 7 5}$ & E379 & & & $\begin{array}{l}\text { Var lation } \\
\text { Explained }\end{array}$ & $\begin{array}{l}\text { Average } \\
\text { Dleference }\end{array}$ \\
\hline Declared Value & 71.64 & 69.46 & 65.15 & 61.36 & 70.54 & 65.65 & 68.38 & 66.22 & & & & \\
\hline $\begin{array}{l}\text { Values Based on } \\
\text { Regression Equat }\end{array}$ & on & 69) .56 & 65.20 & 62.10 & 70.91 & 65.99 & 67.39 & 66.72 & & & 94.3 & 0.88 \\
\hline Difference & +1.2 & +0.1 & +0.1 & +1.2 & +0.5 & -0.5 & -1.5 & +0.8 & & & & \\
\hline
\end{tabular}

1 Filement E374 resulta are based upon itr inclusion in the data analysis.

2 Measured values are hased upon seven elements, with E374 excluded because of irregular irradiation exposure,

3 Burnup values are expressed in grama $235 \mathrm{U}$. 
Both the ${ }^{134} \mathrm{Cs} /{ }^{137} \mathrm{Cs}$ and ${ }^{154} \mathrm{Eu},{ }^{137} \mathrm{Cs}$ activity ratios involve an isotope which is produced via neutron captire reaction on a precursor fission product. The relationships of ${ }^{134} \mathrm{Cs}$ and ${ }^{154} \mathrm{Eu}$ with respect to ${ }^{137} \mathrm{Cs}$ were Investigated by. examining the data obtained in the axial profile measurements. The following functional relationship was evaluated

$$
\left.\left({ }^{134} \mathrm{Cs} \text { or }{ }^{154} \mathrm{Eu}\right)=\alpha t^{137} \mathrm{Cs}\right)^{\mathrm{B}}
$$

where ${ }^{137} \mathrm{Cs}$ is assumed to be directly proportional to the integrated flux and subsequently the burnup. The results from four assemblies are listed in Table $x$.

The data has been presented as a function of burnup in Fig. 17 . The relationship appears to be a function of burnup with decreasing significantly as burnup increases. An exponent of 2.0 should be expected if ${ }^{134} \mathrm{Cs}$ and ${ }^{154}$ Eu were proportional to flux squared, but the exponent for this set of data is generally significantly less than 2.0. If we assume that ${ }^{137} \mathrm{Cs}$ is proportional to flux and burnup is directly related to the integrated flux, then

Burnup $\alpha \frac{134 \mathrm{Cs}}{137 \mathrm{Cs}}$ where ${ }^{134} \mathrm{Cs} \alpha\left(^{137} \mathrm{Cs}\right)^{\mathrm{B}}$

$$
\alpha\left(^{137} \mathrm{Cs}\right)^{\beta-1}
$$

This would imply that burnup is not necessarily a linear function of either the ${ }^{134} \mathrm{Cs} /{ }^{137} \mathrm{Cs}$ or ${ }^{154} \mathrm{Eu} /{ }^{137} \mathrm{Cs}$ isotopic ratio, but rather a power function. The data obtained from the two ${ }^{134} \mathrm{Cs} /{ }^{137} \mathrm{Cs}$ ratios and the ${ }^{154} \mathrm{Eu} /{ }^{137} \mathrm{Cs}$ ratio have been corrected for this dependence and the burnup values recalculated in Table XI. The average differences show a general improvement over the values shown in Table VIII based upon uncorrected values for the isotopes.

Either the corrected or the uncorrected values could probably be used to measure the relative burnup of irradiated fuel assemblies over narrow ranges of burnup. However this may be a problem when measuring fuel assemblies with widely different burnups. The experimenter must be aware of this possible influence when interpreting the data. 


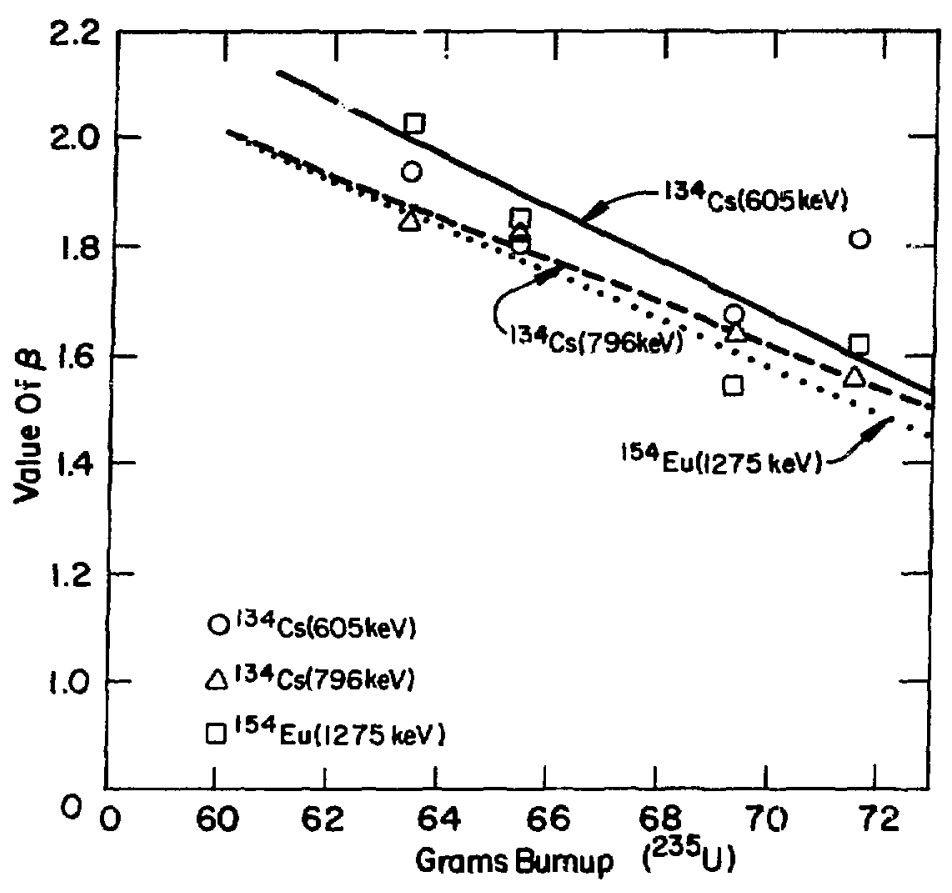

Fig. 17

$\beta$ power factor as a function of declared burnup.

\section{TABLE $X$}

VALUES RELATING $134 \mathrm{Cs}$ AND $154 \mathrm{Eu}$ TO $137 \mathrm{Cs}$

\begin{tabular}{|c|c|c|c|c|}
\hline Element & $\begin{array}{l}\text { Declared } \\
\text { Burnup, g }\end{array}$ & ${ }^{134} \mathrm{Cs}(605)$ & $\begin{array}{l}\text { Factor - B } \\
134 \mathrm{Cs}(796) \\
\end{array}$ & $154 \mathrm{Eu}(1275)$ \\
\hline 383 & 63.37 & $1.94 \pm 0.06$ & $1.85 \pm 0.07$ & $2.03 \pm 0.05$ \\
\hline 378 & 65.37 & $1.81 \pm 0.05$ & $1.82 \pm 0.06$ & $1.83 \pm 0.15$ \\
\hline 363 & 69.27 & $1.67 \pm 0.08$ & $1.64 \pm 0.07$ & $1.54 \pm 0.08$ \\
\hline 357 & 71.64 & $1.83 \pm 0.18$ & $1.56 \pm 0.12$ & $1.61 \pm 0.18$ \\
\hline
\end{tabular}

IV. AXIAL PROFILE MEASUREMENTS

Four irradiated fuel elements were scanned axially using various nondestructive gamma-ray and neutron technicjues to establish their axial burnup profiles. As was discussed previously, axial profile measurements are an integral part of any examination of irradiated fuel elements to ensure the integrity of the entire element and to provide a means of integrating burnup if the burnup is only measured at a single point. The axial distributions of 137 . Cs were used as the standards for comparison. 
TABLE XI

CALCULATED BUPNUP VALUES BASED UPON CORRECTED ${ }^{134}$ Co AND ${ }^{154}$ Eu VAJuUS

September Data

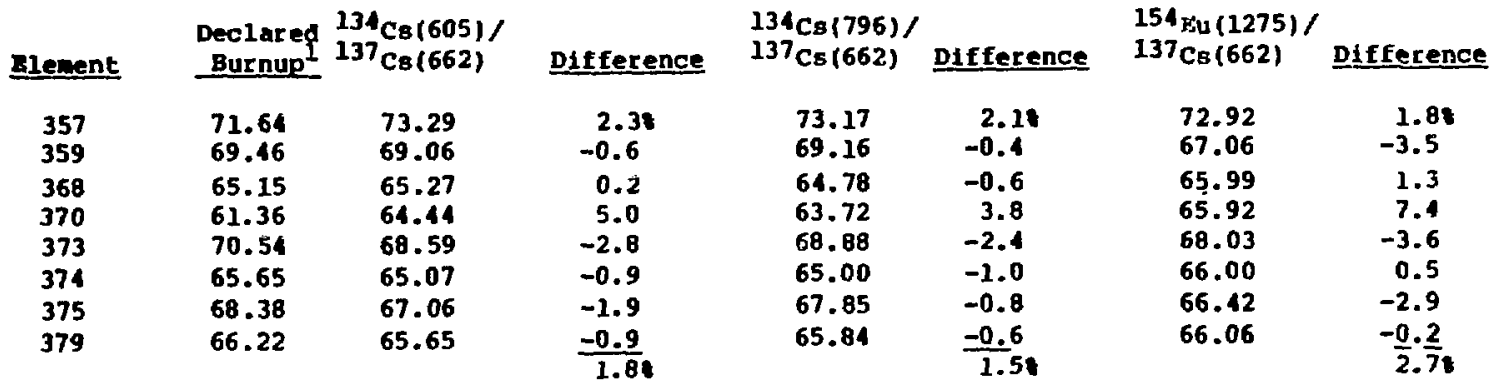

\section{January Data}

$\begin{array}{rrrrrrrr}356 & 73.87 & 75.97 & 2.88 & 75.92 & 2.88 & 74.29 & 0.68 \\ 359 & 69.46 & 67.59 & -2.7 & 67.90 & -2.2 & 68.36 & -1.6 \\ 361 & 67.12 & 65.71 & -2.1 & 65.71 & -2.1 & 64.88 & -3.3 \\ 363 & 69.27 & 67.21 & -3.0 & 67.29 & -2.9 & 67.27 & -2.9 \\ 364 & 63.46 & 64.38 & 1.4 & 64.28 & 1.3 & 64.02 & 0.9 \\ 368 & 65.15 & 64.87 & -0.4 & 64.60 & -0.8 & 64.20 & -1.5 \\ 370 & 61.36 & 63.94 & 4.2 & 63.72 & 3.8 & 63.88 & 4.1 \\ 371 & 61.36 & 64.05 & 4.4 & 63.73 & 3.9 & 63.89 & 4.1 \\ 372 & 70.28 & 68.04 & -3.2 & 68.62 & -2.4 & 72.06 & 2.5 \\ 378 & 65.37 & 64.15 & -\frac{-0.6}{2.53} & 64.94 & -0.7 & 64.26 & -1.7 \\ & & & & & & & \end{array}$

1 Rurnup values are expressed in grams $235 \mathrm{U}$.

\section{A. Germanium}

Individual isotopes and isotopic ratios were correlated with the axial ${ }^{137} \mathrm{Cs}$ data obtained in the september and January exercises. Cluster analysis was used to separate the variables into general groups for further analysis. For each of the four elements the following variables appeared in a group: ${ }^{134} \mathrm{Cs}(605 \mathrm{keV}),{ }^{134} \mathrm{Cs}(796 \mathrm{keV}),{ }^{137} \mathrm{Cs}(652 \mathrm{keV}),{ }^{134} \mathrm{Cs}(796 \mathrm{keV}) /$ ${ }^{144} \mathrm{Pr}(2186 \mathrm{keV}),{ }^{134} \mathrm{Cs}(1365 \mathrm{keV}) /{ }^{144} \mathrm{Pr}(2186 \mathrm{keV})$, and ${ }^{134} \mathrm{Cs}(796 \mathrm{keV}) / 106 \mathrm{Rh}$ (1050 keV). Other variables appeared to be grouped for some elements, but change groups or do not fall into a specific group for all the other elements. The ${ }^{134} \mathrm{Cs}(605 \mathrm{keV}) /{ }^{137} \mathrm{Cs}(662 \mathrm{keV})$ ratio distributions showed the highest degree of correlation with the ${ }^{137} \mathrm{Cs}$ axial activity.

The ${ }^{134} \mathrm{Cs}(605 \mathrm{keV}) /{ }^{137} \mathrm{Cs}(662 \mathrm{keV})$ activity ratio explained at least 918 of the variation in the axial ${ }^{137} \mathrm{Cs}$ activity profile for each of the fuel elements. The data relating the ${ }^{134} \mathrm{cs} /{ }^{137} \mathrm{Cs}$ ratio to ${ }^{137} \mathrm{Cs}$ activity for the axial scan of element E383 are presented in Fig. 18. The 958 confidence 
bounds are plotted around the least squares functions. The standard deviation of the estimate of $Y$ at $X$ (mean) can be interpreted as the spread oi one standard deviation $\left({ }^{137} \mathrm{Cs}\right.$ activity) at the average measured value of ${ }^{134} \mathrm{Cs} /{ }^{137} \mathrm{Cs}$. B. $\operatorname{Be}\left(x_{e} n\right)$ Data

The axial profile of $E 383$ was obtained using the $B e(\gamma, n)$ detection assemb]y Jescribed in the Experimental section (Fig. 4) using various thicknesses of beryllium. Figure 19 shows the results obtained from a 2.5-and 5.0-cm thick beryllium converters with the small fission chamber surrounded with a 4-cm-polyethylene anni?us. The comparison with the ${ }^{137} \mathrm{Cs}$ axial activity profile indicates that inis type of detector could be used to measure the axial burnup profiles of irradiated MTR fuel elements. This detector is primarily sensitive to only the $2186 \mathrm{keV}$ gamma emission of ${ }^{144} \mathrm{Pr}$ as the reaction threshold is $1660 \mathrm{keV}$ for the production of a neutron. The fission chamber used to detect the neutrons is relatively insensitive to the gamma-ray background which can adversely affect other detection devices.

\section{Cadmium Telluride Data}

The cadmium telluride detector was also used to measure the axial gross gamma profile with disappointing results. Extremely high count rates, in excess of 100,000 counts/second, required the movement of the CdTe to distances of 0.3-0.6 meters from the fuel element to reduce saturation problems. Several attempts to shield the cdTe using $2.5-\mathrm{cm}$ of lead and $1.0-\mathrm{cm}$ tungsten were unsuccessful. Operation of the caTe detector in the pulse mode appears to be limited to environments in which the count rate is less than 40,000 counts/ second.

\section{Fission Chamber Data}

A large fission chamber with $1.6 \mathrm{~g}$ of ${ }^{235} \mathrm{U}$ was used to record the axial neutron profile of the E383 element. The MTR fuel was 938 enriched in ${ }^{235} \mathrm{U}$ so the spontaneous neutron emission rate from the higher transuranic isotopes $\left({ }^{238} \mathrm{Pu},{ }^{240} \mathrm{Pu},{ }^{242} \mathrm{Cm}\right.$, and $\left.{ }^{244} \mathrm{Cm}\right)$ should be relatively low when compared to LWR assemblies. The maximum count rate with the fission chamber placed acjjacent to the fuel element was only about 2 cpm. The results obtained from the neutron profile are plotted in Fig. 20 compared to the ${ }^{137}$ Cs activity profile. Production of the spontaneous fissioning isotopes requires multiple neutron interactions, therefore, the $1 / 1.5$ power of the fission chamber aata gave the best fit. The actual power to which the fission chamber results must be raised for the best correlation to the actual burnup profile will depend 


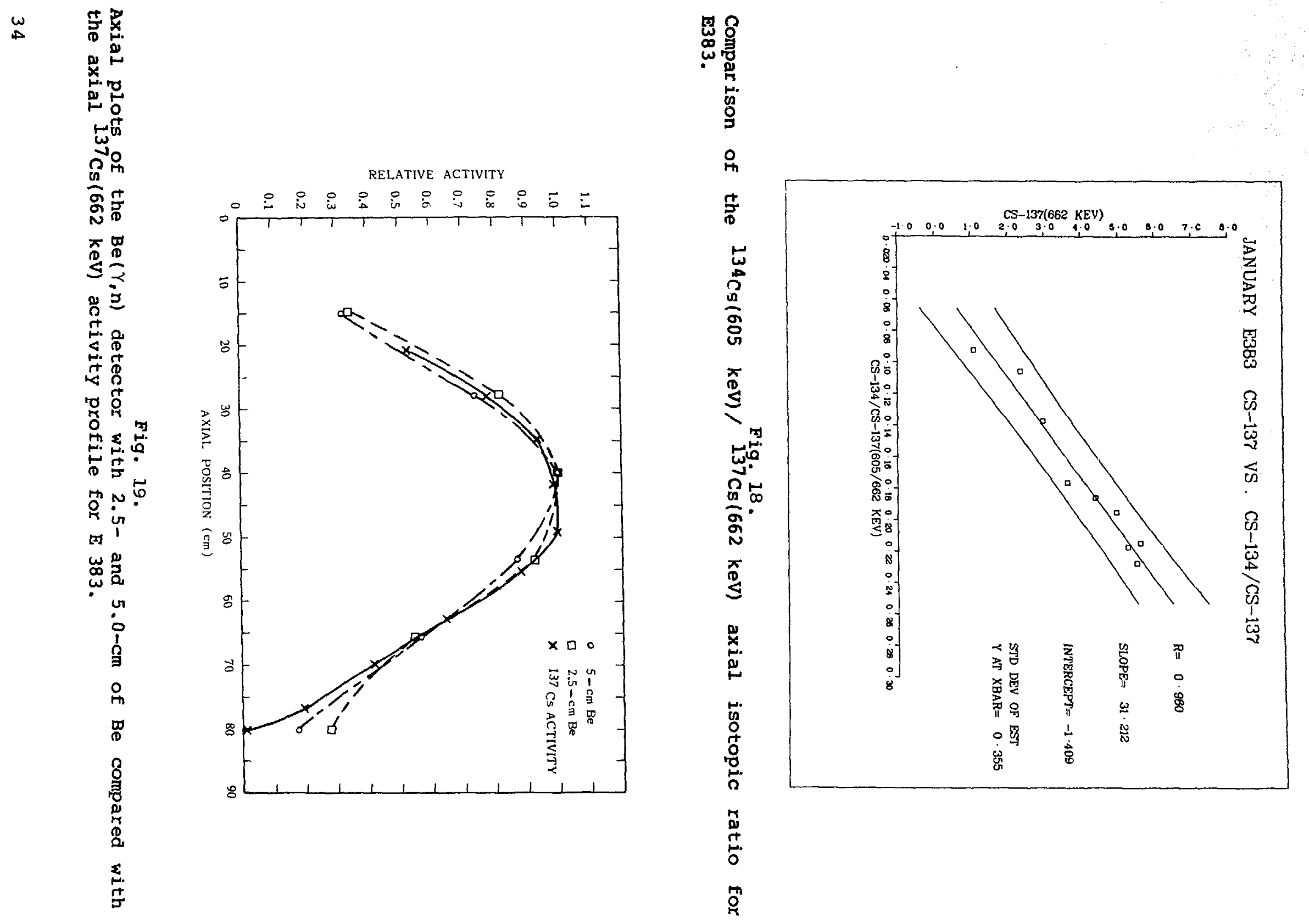




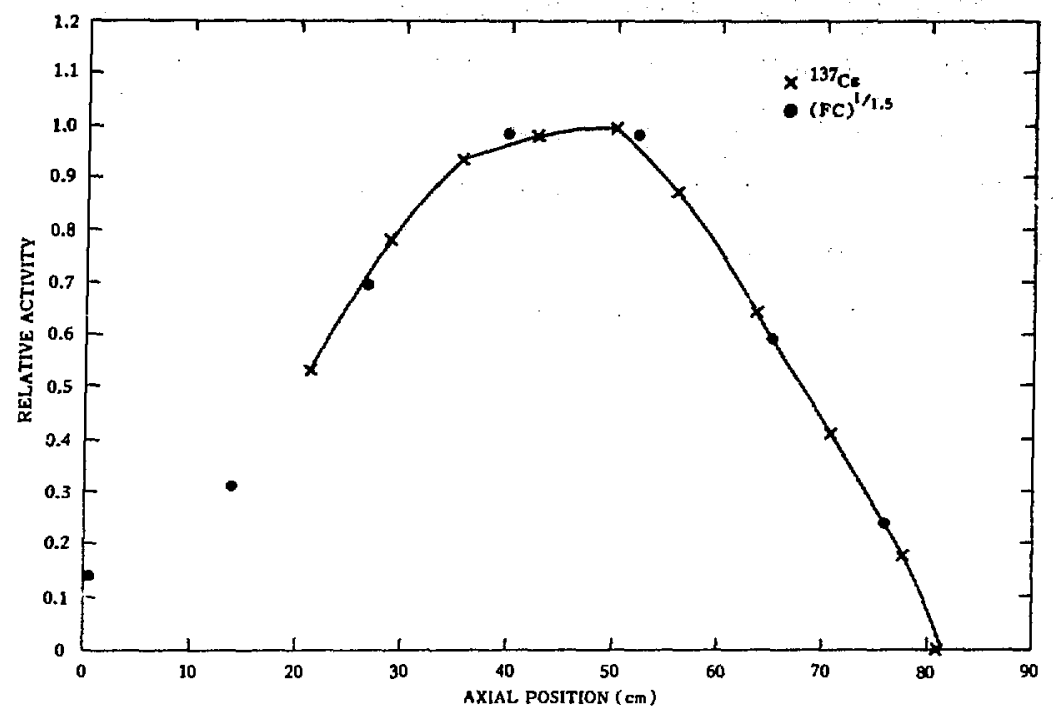

Fig. 20 .

Comparison of $137 \mathrm{Cs}$ axial profile with the neutron results raised to the $1 / 1.5$ power.

upon the irradiation environment of the fuel element as well as the initial isotopic composition of the uranium. Also, the fission chamber is an uncollimated detector, that is, an extended detector looking at an extended source. These results should not be interpreted as quantitative but rather as an indication of the application of neutron techniques to profile and relative burnup measurement of irradiated fuel elements.

\section{v. CONCLUSTONS}

Various nondestructive gamma-ray and neutron techniques were applied to the characterization of the cooling times and burnups of irradiated MTR fuel elements. The correlation of all the major full-energy gamma-ray peaks and many isotopic ratios with these parameters were investigated using multivariate techniques to divide the number of independent variables into smaller groupings. Principal component analysis provided the number of dimensions required to contain most of the variations and cluster analysis provided a qualitative grouping of predictor variables. Both these statistical techniques were used to identify variables that should be investigated to quantify the prediction of relative cooling times and burnup values. 
A nonlinear and linear model were investigated to represent the relationship between the measured variables and the declared cooling times. For the nonlinear model using known decay constants, the predicted values differed from the declared values by approximately 78 fur single isotopes and by about 58 for isotopic ratios. By using regression analysis to calculate the coefficients the differences between predicted and declared values were reduced to about 48 for ooth single isotopes and isotopic ratios. In the nonlinear model the ${ }^{144} \mathrm{Pr} /{ }^{137} \mathrm{Cs}$ ratio consistently provided better prediction capability than any cif the other isotopes or ratios. The half-life of ${ }^{144} \mathrm{Ce}$, the parent of ${ }^{14} \mathrm{Pr}$, is 284.4 days which is comparable to the cooling times measured. For shorter cooling times other isotopes ${ }^{95} \mathrm{zr} ; t_{\frac{1}{2}}=65.5$ days, and ${ }^{140} \mathrm{Ba}-\mathrm{La}: t_{\mathrm{l}}=12.8$ days) may be better predictors, similarly for longer cooling times ${ }^{137} \mathrm{Cs}\left(t_{z_{2}}=30.12 \mathrm{y}\right),{ }^{154} \mathrm{Eu}\left(t_{\frac{1}{2}}=8.6 \mathrm{y}\right)$, and ${ }^{134} \mathrm{Cs}\left(t_{z_{2}}=2.06 \mathrm{y}\right) \mathrm{might}$ have to be used. The ${ }^{134} \mathrm{Cs}$ and ${ }^{154} \mathrm{Eu}$ isotopes may be dependent upon the burnup of the fuel assemblies as was discussed in the axial profile section. In the linear model the independent variables, ${ }^{134} \mathrm{Cs} /{ }^{137} \mathrm{Cs}$ and ${ }^{154} \mathrm{Eu} /{ }^{144} \mathrm{Pr}$ exhibited the highest level of cor relaticn for these ranges of cooling times. The ${ }^{137} \mathrm{Cs}$ activity and three isotopic ratios, ${ }^{134} \mathrm{Cs}(605) /{ }^{137} \mathrm{Cs}(662)$, ${ }^{134} \mathrm{Cs}(796) /{ }^{137} \mathrm{Cs}(662)$, and ${ }^{154} \mathrm{Eu}(1275) /{ }^{137} \mathrm{Cs}(662)$, had the best correlations with the declared burnup values for both exercises. Using a linear combination of the four variables over 808 and 978 of the variations in the September and January data, respectively, could be explained using a linear model. The use of ratios or linear combinations as a consistency measurement is feasible with an uncertainty ranging from 2 to 4 grams for an average burnup value of 66 grams. This corresponds to a relative precision of 3-68 over the range of burnup values measured.

The functional relationships of the shielded isotopes ${ }^{134} \mathrm{Cs}$ and ${ }^{154} \mathrm{Eu}$ with respect to ${ }^{137} \mathrm{Cs}$ were shown to be a power function, with the exponent possibly being a function of burnup. Additional data will have to be analyzed before a definitive relationship can be established.

The axial burnup profile is required if we are to relate a single point measurement of burnup to the entire fuel element. A $B e(\gamma, n)$ detector was used to measure the high-energy (>1.66 MeV) gamma profile of the irradiated elements. The high ${ }^{235} \mathrm{v}$ enrichment resulted in little buildup of even-numbered spontaneous fissioning isotopes within the fuel material. A fission chamber 
monitored the axial neutron profile, which was a power relationship when correlased with the ${ }^{137} \mathrm{Cs}$ profile. Cadmium telluride detectors were of limited use in the pulse mode because of the very high gamma environments which saturated the detector.

The data obtained from these exercises will be used as input for the design and evaluation of similar measurements to be performed on light water reactor fuels. Similar statistical analyses will be applied to future data sets to determine consistency trends between measured variables and the important safeguard parameters: cooling times, axial profiles, and burnup values.

\section{ACKIOWIEDGEMENTS}

The assistance of the Omega West Reactor operations staff and particularly H. T. Williams and A. R. Lyle, was essential for the successful completion of this investigation. Mechanical support from L. R. Cowder, H. R. Dye, and D. c. Garcia in the construction and installation of the equipment was gratefully appreciated.

\section{REFERENCES}

1. "A Short History of Nonproliferation," International Atomic Enes yy Agency report IAEA-575 (February 1976)。

2. Nucleonics Week, August 24, 1978 Vol. i9, No. 34, McGraw-Hill, New York.

3. S. T. Hsue, T. W. Crane, W. L. Talbert, Jr., J. C. Lee, "A Review of Nondestructive Assay Methods for Irradiated Nuclear Fuel," Los Alamos Scientific Laboratory report LA-6923 (December 1977).

4. T. Dragnev, R. Diaz-Duque, B. Pontes, "Safeguards Gamma Measurements on Spent MTR Fuel," International Atomic Energy Agency report IAEA/STR-4I (May 1973).

5. C. Beets, P. Bemelmans, T. Dragnev, R. Hecq, "Gamma Measurements on Spent Fuel Elements," ANS International Meeting, Safeguards and Nondestructive Assay Technology, Washington, D.C. (November 23, 1972).

6. G. L. Hanna, "Gamma-Ray Measurement of Spent HTFAR Fuel Elements for Safeguards Verification: Part 1. Experimental Evaluation of Method," ASO/R2 (July 1978).

7. G. L. Hanna, "Gamma-Ray Measurement of Spent HTFAR Fuel Elements for Safeguards Verification: Part II. Theoretical Evaluation of Method," ASO/R2 (July 1978). 
8. J. D. Chen, D. G. Bosge, R. B. Lypka, D. G. Zetaruk, "Hondestructive Determination of Burnup by Gama Scanning: An Exanination of $14 \mathrm{Ce} / \mathrm{Pr}$ and $134 \mathrm{Cs} / 137 \mathrm{Cs}$ as Fission Monitors in CANDU Fuels," ABCL report (1978).

9. J. Valovic, V. Petenyi, S. B. Rana, D. Mikusova, J. Kosena, The Application of Gamma and Isotopic Correlation Techniques for Safeguards Identification and Verification Purposes," International Atomic Energy Agency research contract 1443, Bohunice Nuclear Power Plant, Bohunice, Czechoslovakia (1975).

10. H. T. Williams, A. R. Lyle, O. W. Stopinski, C. L. Warner, Y. L. Yarnell, H. L. Maine, "1969 Status Report on the Omega hest Reactor, with Revised Safety Analysis," Los Alamos Scientific Laboratory report LA-4192 (July 1969).

11. J. R. Beyster, L. A. Rull, "Safeguards Applications for Isotopic Neutron Sources," Brookhaven National Laboratory report BNL-50267 (T-596) (June $1970)$.

12. Chart of Nuclides, 12th Edition, Knolls Atomic Power Laboratory (April 1977).

13. N. R. Draper and H. Smith, Applied Regression funalysis, John Wiley and Sons, Inc., New York (1966).

14. D. F. Morrison, Multivariate Statistical Methods, McGraw-Fill, New York (1967).

15. P. H. A. Sneath and R. R. Sokel, Numerical Taxonomy, W. B. Freenan and Co., San Francisco (1973).

16. M. R. Anderberg, Cluster Analysis for Applications, Academic Press, New York (1973). 